\title{
Synthesis of sulfonyl chlorides from aryldiazonium salts mediated by heterogeneous potassium poly(heptazine imide) photocatalyst
}

\author{
Yevheniia Markushyna, ${ }^{*}$ Markus Antonietti and Aleksandr Savateev* \\ Max-Planck Institute of Colloids and Interfaces, Department of Colloid Chemistry, Am Mühlenberg \\ 1, 14476 Potsdam, Germany
}

\section{Supporting information}

\section{Chemicals}

All chemicals were used without purification. Acetonitrile ( $\geq 99.8 \%$, Sigma Aldrich), chloroform- $d$ (99.8 atom\% D, Sigma Aldrich), dichloromethane ( $\geq 99.9 \%$, Sigma Aldrich), dimethylsulfoxide- $d_{6}$ (99.5 atom \% D, Sigma Aldrich), thionyl chloride (99\%, Sigma Aldrich), aniline (99\%, Alfa Aesar), 4-bromoaniline (99\%, TCl), 4-chloroaniline (99\%, TCl), p-anisidine (99\%, Alfa Aesar), 4aminobenzonitrile (98\%, TCI), methyl 4-aminobenzoate (98\%, Sigma Aldrich), 4-nitroaniline (99\%, Sigma Aldrich).

\section{Characterization methods}

${ }^{1} \boldsymbol{H}$ and ${ }^{13} \mathrm{C}$ NMR spectra were recorded on an Agilent $400 \mathrm{MHz}$ (at $400 \mathrm{MHz}$ for Protons and $101 \mathrm{MHz}$ for Carbon-13). NMR spectra were recorded in $\mathrm{CDCl}_{3}$ or DMSO-d6. The chemical shifts are reported in ppm relative to the residual signal of $\mathrm{CHCl}_{3}\left(7.26 \mathrm{ppm}\right.$ in ${ }^{1} \mathrm{H} \mathrm{NMR}, 77.16 \mathrm{ppm}$ for ${ }^{13} \mathrm{C}$ NMR) or DMSO (2.5 ppm in ${ }^{1} \mathrm{H}$ NMR, $39.52 \mathrm{ppm}$ for ${ }^{13} \mathrm{C}$ NMR).

GC-MS. Agilent 6890 Network GC System coupled with Agilent 5975 Inert Mass Selective detector (electron ionization) were used for reaction mixture composition analysis and to obtain mass spectra of the products.

Fourier transform infrared (FT-IR) spectra were recorded on Thermo Scientific Nicolet iD5 spectrometer.

Optical absorbance spectra of powders were measured on a Shimadzu UV 2600 equipped with an integrating sphere in diffuse reflectance mode.

Steady-state fluorescence spectra were measured on Jasco FP-8300 fluorescence spectrometer. 
Powder X-Ray diffraction patterns were measured on a Bruker D8 Advance diffractometer equipped with a scintillation counter detector with CuKa radiation $(\lambda=0.15418 \mathrm{~nm})$ applying $2 \theta$ step size of $0.05^{\circ}$ and counting time of 3 s per step.

Nitrogen adsorption/desorption measurements were performed after degassing the samples at $150{ }^{\circ} \mathrm{C}$ for 20 hours using a Quantachrome Quadrasorb SI-MP porosimeter at $77.4 \mathrm{~K}$. The specific surface areas were calculated by applying the Brunauer-Emmett-Teller (BET) model to adsorption isotherms for $0.05<\mathrm{p} / \mathrm{p}_{0}<0.3$ using the QuadraWin 5.11 software package.

Scanning electron microscopy (SEM) images were obtained on JSM-7500F (JEOL) microscope. Energy disperse X-ray (EDX) analysis and morphology observation by scanning electron microscope (SEM) were performed using a Link ISIS-300 system (Oxford Microanalysis Group).

X-ray photoelectron spectroscopy (XPS) measurements were carried out in an ultrahigh vacuum (UHV) spectrometer equipped with a VSW Class WA hemispherical electron analyzer. A dual anode Al Ka X-ray source (1486.6 eV) was used as incident radiation. Survey and high resolution spectra were recorded in constant pass energy mode ( 44 and $22 \mathrm{eV}$, respectively). During the UPS (He I excitation energy hv=21.23 eV) measurements a bias of $15.32 \mathrm{~V}$ was applied to the sample, in order to avoid interference of the spectrometer threshold in the UP spectra. The values of the valence band maximum (VBM) are determined by fitting a straight line into the leading edge.

TEM measurements were acquired using a double-corrected JEOL JEM-ARM200F, equipped with a cold field emission gun and a Gatan GIF Quantum.

\section{Photocatalysts preparation}

\section{K-PHI preparation}

$\mathrm{K}-\mathrm{PHI}$ was prepared according to the literature procedure. ${ }^{1} \mathrm{~A}$ mixture of lithium chloride $(3.71 \mathrm{~g})$, potassium chloride $(4.54 \mathrm{~g}$ ) and 5 -aminotetrazole $(1.65 \mathrm{~g}$ ) was ground in ball mill for $5 \mathrm{~min}$ at the shaking rate $25 \mathrm{~s}^{-1}$. Reaction mixtures were transferred into porcelain crucibles and covered with lids. Crucibles were placed in the oven and heated under constant nitrogen flow (15 L· $\left.\mathrm{min}^{-1}\right)$ and atmospheric pressure at a following temperature regime: heating from room temperature to $550{ }^{\circ} \mathrm{C}$ for 4 hours, annealing at $550^{\circ} \mathrm{C}$ for 4 hours. After completion of the heating program, the crucibles were allowed to cool slowly to room temperature under nitrogen flow. The crude products were removed from the crucibles, washed with deionized water $(100 \mathrm{~mL})$ for 3 hours in order to remove salts, then filtered, extensively washed with deionized water and dried in a vacuum oven ( $20 \mathrm{mbar}$ ) at $50{ }^{\circ} \mathrm{C}$ for $15 \mathrm{~h}$. 

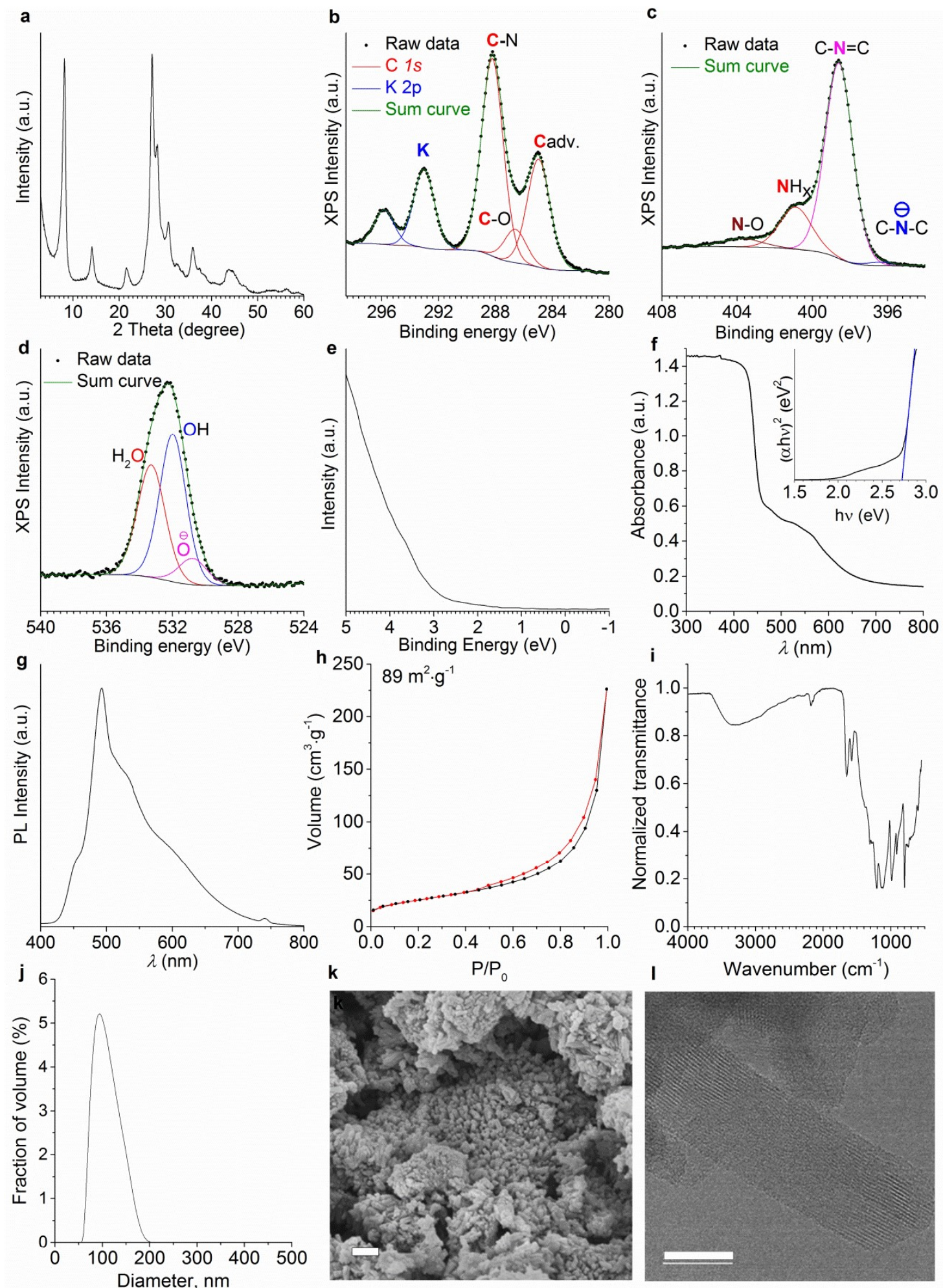

Figure S1. K-PHI characterization. a) PXRD pattern of K-PHI; b) XPS C 1s and K 2p spectra of K-PHI; c) XPS N 1s spectrum of K-PHI; d) XPS O 1s spectrum of K-PHI; e) UPS spectrum of K-PHI; f) UV-vis absorption spectrum of K-PHI with Tauc plot as inset assuming that K-PHI is a direct semiconductor; g) PL spectrum of K-PHI obtained upon excitation with $350 \mathrm{~nm}$; h) $\mathrm{N}_{2}$ sorption isotherm measured at $77 \mathrm{~K}$. BET surface area; i) FT-IR spectrum of K-PHI; j) Dynamic light scattering (DLS) analysis of K-PHI suspension in water; k) representative SEM image of K-PHI photocatalyst. Scale bar $200 \mathrm{~nm}$; I) AC-HRTEM image of K-PHI photocatalyst. Scale bar 20 nm. Reproduced from Nat Commun 10, 945 (2019). ${ }^{2}$ 


\section{g-CN preparation}

g- $\mathrm{CN}$ was prepared according to the following procedure. Dicyandiamide (15 g) was heated to $600{ }^{\circ} \mathrm{C}$ with a ramp $2.4{ }^{\circ} \mathrm{C}$ under $\mathrm{N} 2$ flow. After cooling to room temperature, solid was finely ground in mortar.

\section{mpg-CN preparation}

mpg-CN was prepared according to the procedure described in literature. ${ }^{3}$ Cyanamide $(3.0 \mathrm{~g})$ and Ludox HS-40 (7.5 g) were mixed in a $10 \mathrm{~mL}$ glass vial. The mixture was stirred at room temperature for 30 min until cyanamide has completely dissolved. The resultant solution was stirred at $+60^{\circ} \mathrm{C}$ for $16 \mathrm{~h}$ until water has completely evaporated. The magnetic stirrer bar was removed and white solid was transferred to the porcelain crucible and heated under $\mathrm{N}_{2}$ flow in the oven. The temperature was increased from room temperature to $550^{\circ} \mathrm{C}$ within $4 \mathrm{~h}$ and maintained at $550^{\circ} \mathrm{C}$ for $4 \mathrm{~h}$. The crucible was spontaneously cooled to room temperature. The solid from the crucible was briefly grinded in the mortar and transferred to the polypropylene bottle. A solution of $\left(\mathrm{NH}_{4}\right) \mathrm{HF}_{2}\left(0.24 \mathrm{~g} \cdot \mathrm{mL}^{-1}, 50 \mathrm{~mL}\right)$ was added and suspension was stirred at room temperature for $24 \mathrm{~h}$. The solid was filtered, thoroughly washed with water, once with ethanol and dried in vacuum $\left(55^{\circ} \mathrm{C}, 20 \mathrm{mbar}\right)$ overnight.

\section{$\mathrm{Na}-\mathrm{PHI}$ preparation}

$\mathrm{Na}$-PHI was prepared according to the literature procedure. ${ }^{4}$ Melamine $(1 \mathrm{~g})$ was grinded with $\mathrm{NaCl}$ (10 g). Reaction mixture was transferred into a porcelain crucible and covered with lid. Crucible was placed in the oven and heated under constant nitrogen flow $\left(15 \mathrm{~L} \cdot \mathrm{min}^{-1}\right)$ to $600{ }^{\circ} \mathrm{C}$ with a heating rate of $2.3^{\circ} \mathrm{C} / \mathrm{min}$, held at $600^{\circ} \mathrm{C}$ for 4 hours, then allowed to cool down. The crude product was removed from the crucible, washed with deionized water $(100 \mathrm{~mL})$, isolated by filtration, then thoroughly washed with deionized water on the filter $(100 \mathrm{~mL})$ and dried in a vacuum oven at $50^{\circ} \mathrm{C}$ for $15 \mathrm{~h}$.

\section{Possible products of the Meerwein type chlorosulfonylation}

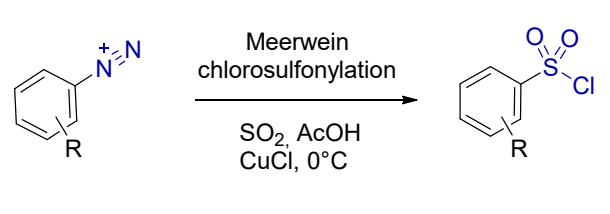

target product
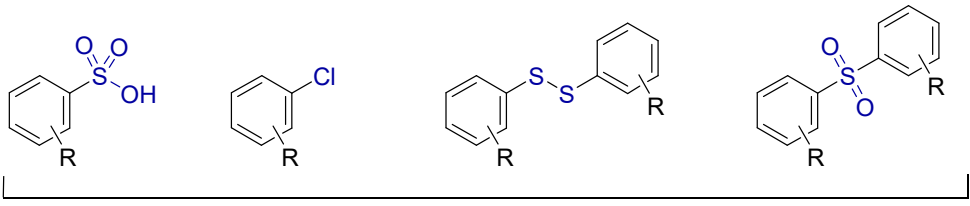

side products

Scheme S1. Possible products of the Meerwein type chlorosulfonylation 


\section{Water content in acetonitrile}

Table S1. Water content in MeCN analyzed by Karl-Fischer titration

\begin{tabular}{l|l|l|l} 
Component & $\mathbf{H}_{\mathbf{2}} \mathbf{O}$ content, $\mathbf{p p m}$ & $\mathbf{V}_{\text {component }} \mathbf{~} \mathbf{L L}$ & Amount of $\mathbf{H}_{\mathbf{2}} \mathbf{O}, \boldsymbol{\mu m o L}$ \\
\hline MeCN & 640 & 1 & 35.5 \\
\hline Anhydrous MeCN & 252 & 1 & 14
\end{tabular}

\section{Reaction with DABSO}

A glass vial was charged with 4-chlorophenyldiazonim tetrafluoroborate 1f $(0.025 \mathrm{mmol}), \mathrm{K}-\mathrm{PHI}$ $(4 \mathrm{mg})$, acetonitrile $(1 \mathrm{~mL})$ and the solution was purged with $\operatorname{Ar}$ for $5 \mathrm{~min}$. Then, DABSO $(0.125 \mathrm{mmol})$ and $2 \mathrm{M} \mathrm{HCl}$ in $\mathrm{Et}_{2} \mathrm{O}(62 \mu \mathrm{L}, 0.125 \mathrm{mmol})$ were added. The reaction mixture was stirred under blue LED irradiation $\left(465 \mathrm{~nm}, 46 \mathrm{~mW} \cdot \mathrm{cm}^{-2}\right)$ at room temperature for $24 \mathrm{~h}$. After the irradiation solution was concentrated under reduced pressure and analyzed by GC-MS.
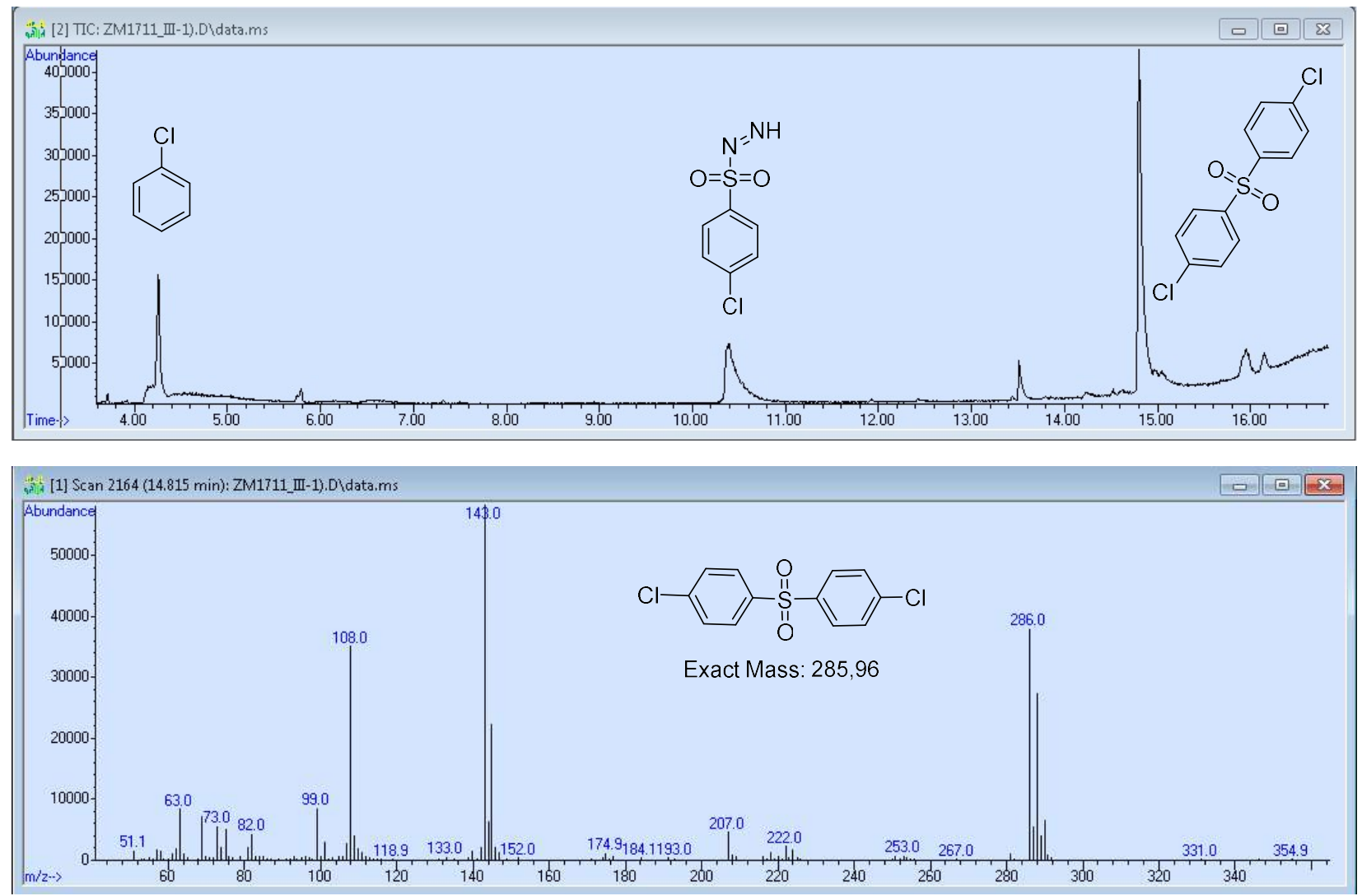

Figure S2. GC-MS chromatogram of the reaction mixture prepared with DABSO and MS spectrum of the main product. A peak with retention time of ca. 10.5 min was tentatively assigned to ((4chlorophenyl)sulfonyl)diazene. ${ }^{5}$ 



\section{Synthesis methods}

\section{Synthesis of arenediazonium tetrafluoroborates 1}

The diazonium salts have been prepared according to the reported procedure. ${ }^{6}$ Typically, a solution of $\mathrm{NaNO}_{2}(0.69 \mathrm{~g}, 10 \mathrm{mmol})$ was added dropwise to a cooled on the ice bath solution of arylamine $(10 \mathrm{mmol})$ in $\mathrm{HBF}_{4}(3.54 \mathrm{~mL}, 27 \mathrm{mmol})$ upon stirring. The reaction mixture was stirred on the ice bath for additional $2 \mathrm{~h}$. Precipitate was separated by filtration, dissolved in acetone $(150 \mathrm{~mL})$ and maintained at $-20^{\circ} \mathrm{C}$ overnight. Transparent crystals precipitated. Diethylether $\left(200 \mathrm{~mL}\right.$ ) was added and suspension was maintained at $-20^{\circ} \mathrm{C}$ for $1 \mathrm{~h}$, solid was separated by filtration, washed with cold diethylether (2 times $5 \mathrm{~mL}$ ) and dried on filter.

\section{4-bromobenzenediazonium tetrafluoroborate 1a}

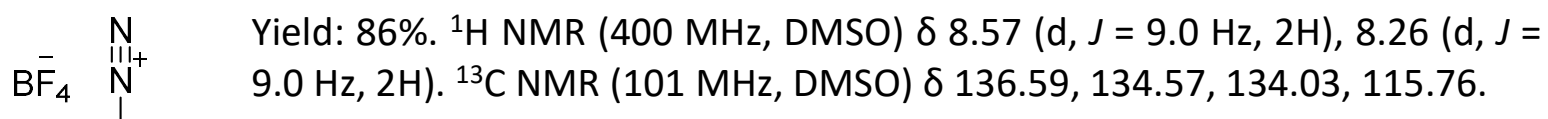

4-methoxybenzenediazonium tetrafluoroborate $\mathbf{1 b}$

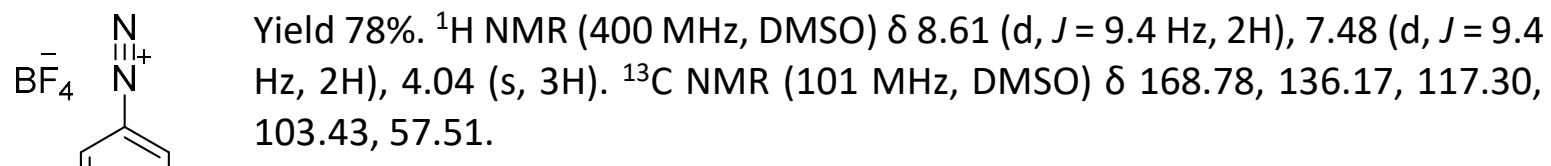

4-cyanobenzenediazonium tetrafluoroborate 1c

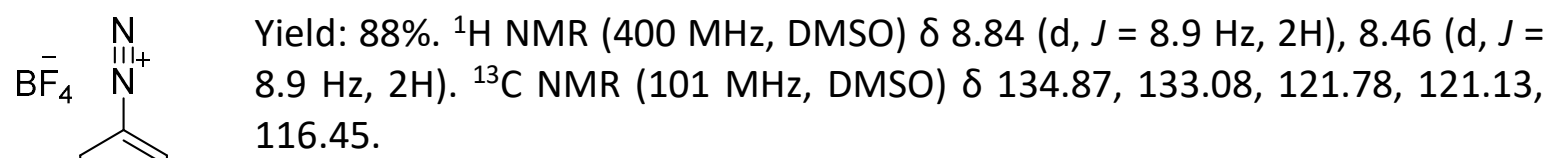

4-(methoxycarbonyl)benzenediazonium tetrafluoroborate $\mathbf{1 d}$

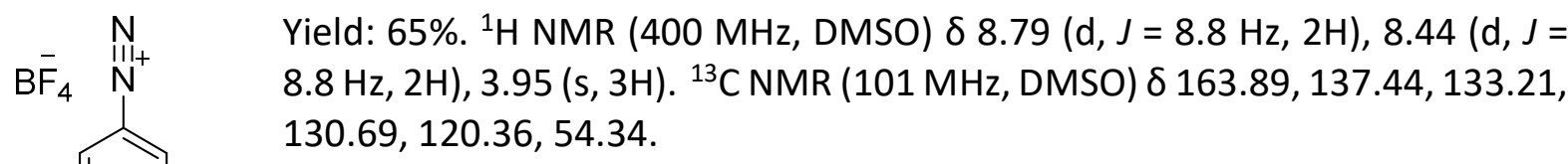


Benzenediazonium tetrafluoroborate 1e

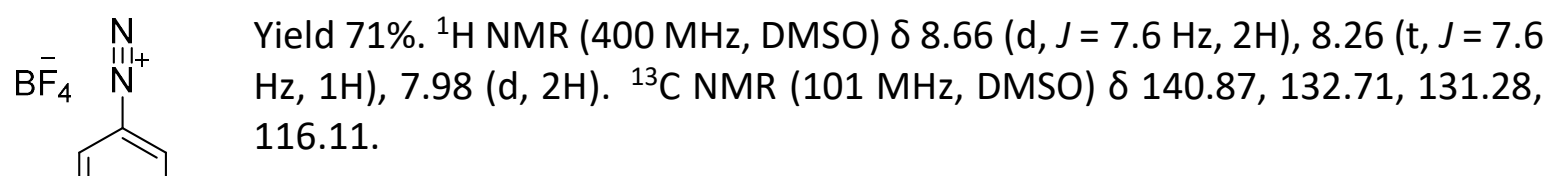

4-chlorobenzenediazonium tetrafluoroborate $1 \mathbf{f}$

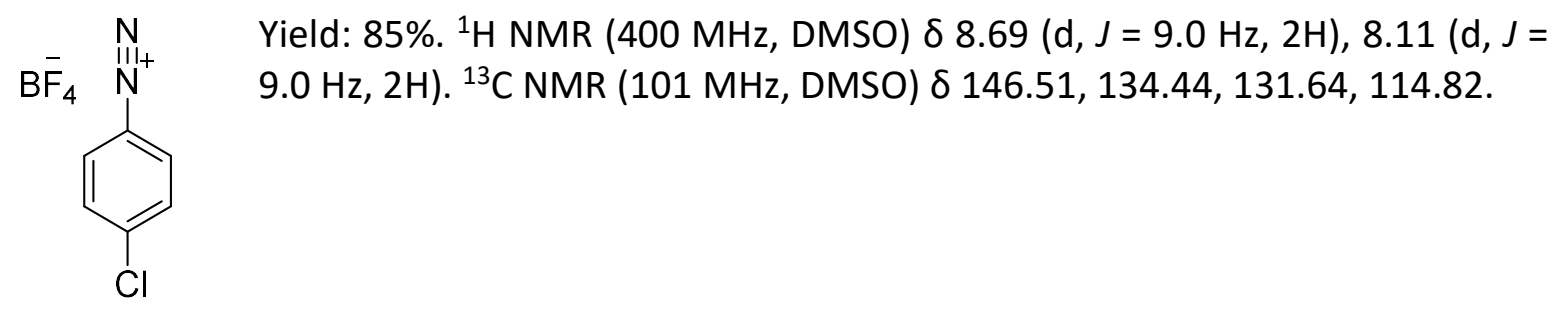

4-nitrobenzenediazonium tetrafluoroborate $\mathbf{1 g}$

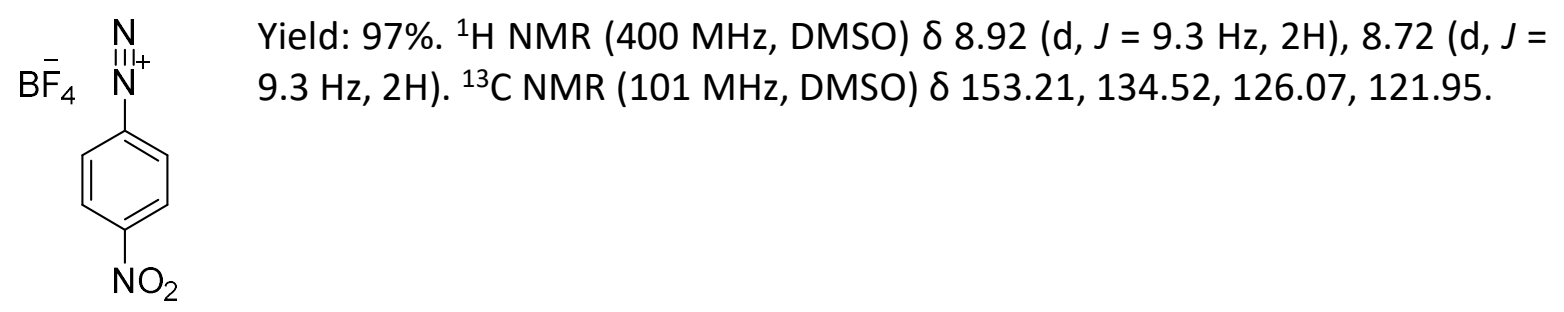

4-chloro-3-(trifluoromethyl)benzenediazonium tetrafluoroborate $1 \mathrm{~h}$

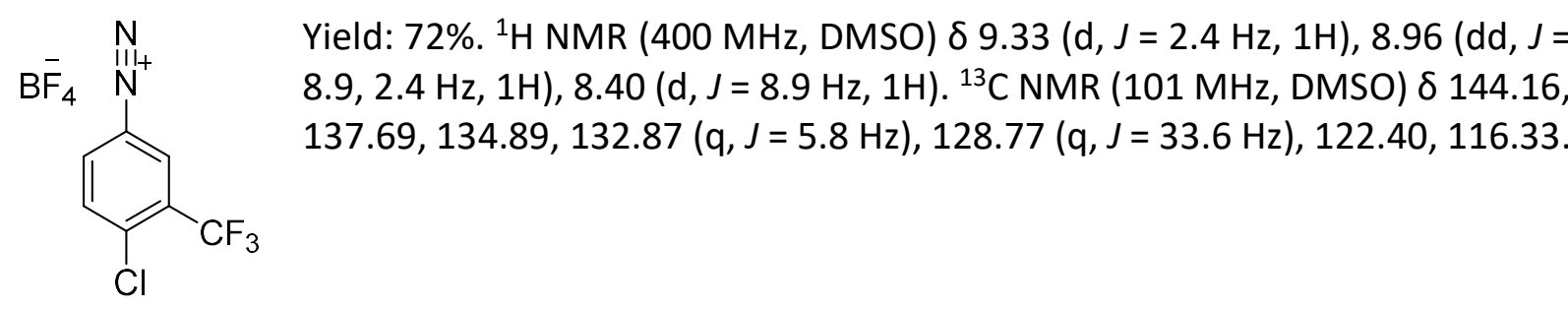

3-nitrobenzenediazonium tetrafluoroborate $\mathbf{1 i}$

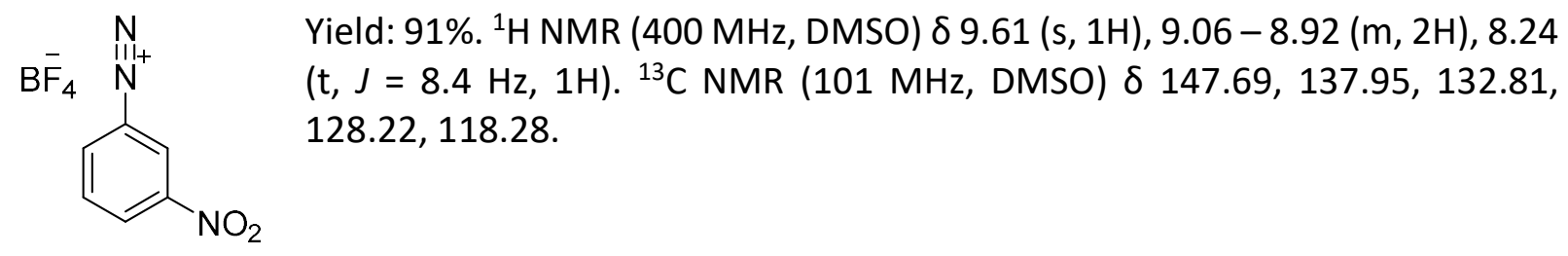

2-fluorobenzenediazonium tetrafluoroborate $\mathbf{1 j}$

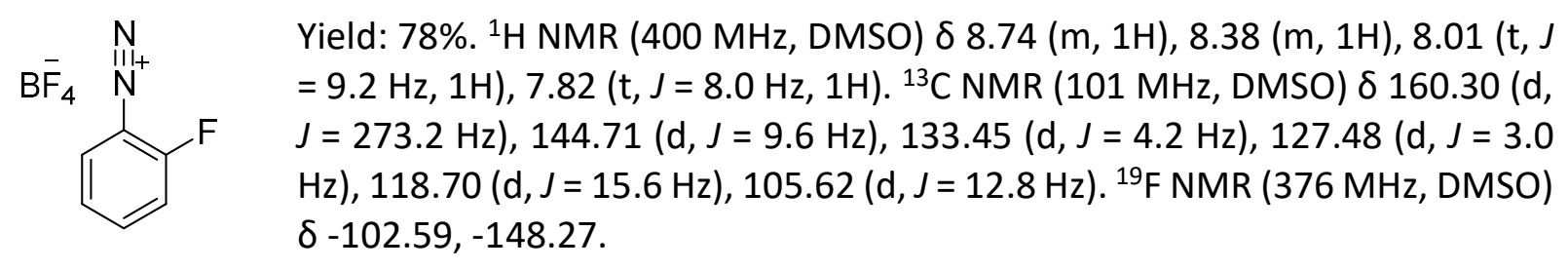




\section{Synthesis of sulfonylchlorides 2}

A glass vial was charged with arenediazonium salt $1(0.025 \mathrm{mmol})$, and K-PHI $(4 \mathrm{mg})$, acetonitrile $(1 \mathrm{~mL}$ ) (or dichloromethane for phenyldiazonium tetrafluoroborate 1e) and the solution was purged with Ar for $5 \mathrm{~min}$. Then, water $\left(5 \mu \mathrm{L}, 0.28 \mathrm{mmol}\right.$ ) and $\mathrm{SOCl}_{2}(19 \mu \mathrm{L}, 0.16 \mathrm{mmol}$ ) were added. The reaction mixture was stirred under blue LED irradiation $\left(465 \mathrm{~nm}, 46 \mathrm{~mW} \cdot \mathrm{cm}^{-2}\right)$ at room temperature for $24 \mathrm{~h}$. After the irradiation solution was concentrated under reduced pressure and analyzed by NMR.

\section{4-bromobenzenesulfonyl chloride $\mathbf{2 a}$}

O" $-\mathrm{Cl} \quad{ }^{1} \mathrm{H}$ NMR $\left(400 \mathrm{MHz}, \mathrm{CDCl}_{3}\right) \delta 7.91(\mathrm{~d}, J=8.8 \mathrm{~Hz}, 2 \mathrm{H}), 7.77(\mathrm{~d}, J=8.8 \mathrm{~Hz}, 2 \mathrm{H})$. Spectrum matches reported earlier in reference ${ }^{7}$.<smiles>Brc1ccccc1</smiles>

4-methoxybenzenesulfonyl chloride $\mathbf{2 b}$

O= $\mathrm{O}=\mathrm{S} \quad 3.74(\mathrm{~s}, 3 \mathrm{H})$. Spectrum matches reported earlier in reference ${ }^{8}$.<smiles>COc1ccccc1</smiles>

4-cyanobenzenesulfonyl chloride 2c

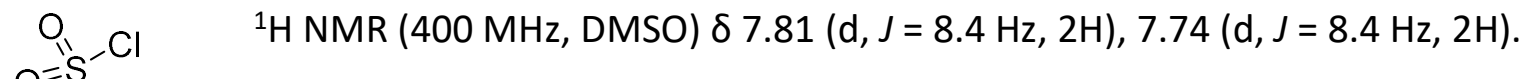<smiles>N#Cc1ccc(S(=O)(=O)Cl)cc1</smiles>

4-(methoxycarbonyl)benzene sulfonyl chloride $\mathbf{2 d}$

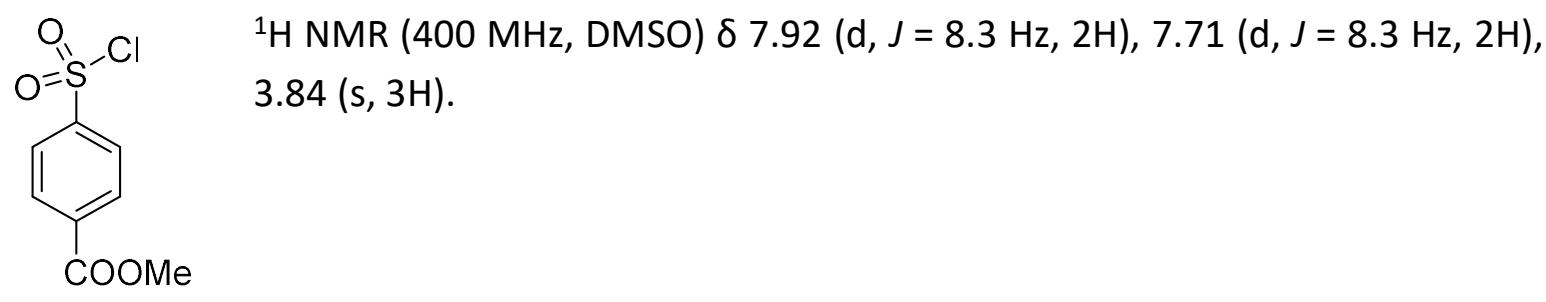


4-chlorobenzenesulfonyl chloride $\mathbf{2 f}$

O ${ }^{1} \mathrm{H}$ NMR (400 MHz, DMSO) $\delta 7.63-7.55(\mathrm{~m}, 2 \mathrm{H}), 7.37(\mathrm{~d}, J=8.5 \mathrm{~Hz}, 2 \mathrm{H})$. $\mathrm{O}=\mathrm{S}^{-\mathrm{Cl}} \quad$ Spectrum matches reported earlier in reference ${ }^{9}$<smiles>Clc1ccccc1</smiles>

4-nitrobenzenesulfonyl chloride $\mathbf{2 g}$

O<smiles>O=[N+]([O-])c1ccc(S(=O)(=O)Cl)cc1</smiles>

4-chloro-3-(trifluoromethyl)benzenesulfonyl chloride $\mathbf{2 h}$

O<smiles>O=S(=O)(Cl)c1ccc(Cl)c(C(F)(F)F)c1</smiles>

$8.3 \mathrm{~Hz}, 1 \mathrm{H})$.

3-nitrobenzenesulfonyl chloride $\mathbf{2 i}$

O $\quad{ }^{1} \mathrm{H}$ NMR $(400 \mathrm{MHz}, \mathrm{DMSO}) \delta 8.34(\mathrm{~s}, 1 \mathrm{H}), 8.19(\mathrm{~d}, J=9.3 \mathrm{~Hz}, 1 \mathrm{H}), 8.02(\mathrm{~d}, J=$<smiles>O=[N+]([O-])c1cccc(S(=O)(=O)Cl)c1</smiles>

$7.6 \mathrm{~Hz}, 1 \mathrm{H}), 7.66(\mathrm{t}, J=7.9 \mathrm{~Hz}, 1 \mathrm{H})$.

2-fluorobenzenesulfonyl chloride $2 \mathbf{j}$

Oㄱ, $\quad{ }^{1} \mathrm{H}$ NMR (400 MHz, DMSO) $\delta 7.67(\mathrm{t}, J=7.6 \mathrm{~Hz}, 1 \mathrm{H}), 7.43-7.31(\mathrm{~m}, 1 \mathrm{H}), 7.16$<smiles>O=S(=O)(Cl)c1ccccc1F</smiles>

$-7.07(\mathrm{~m}, 2 \mathrm{H})$. 


\section{Supplementary Note 1}

For the case with phenyldiazonium tetrafluoroborate $1 \mathbf{e}$ reaction was carried out in dichloromethane, as it reacts with acetonitrile to form phenylacetamide, ${ }^{1} \mathrm{H}$ NMR spectra of which is presented below.
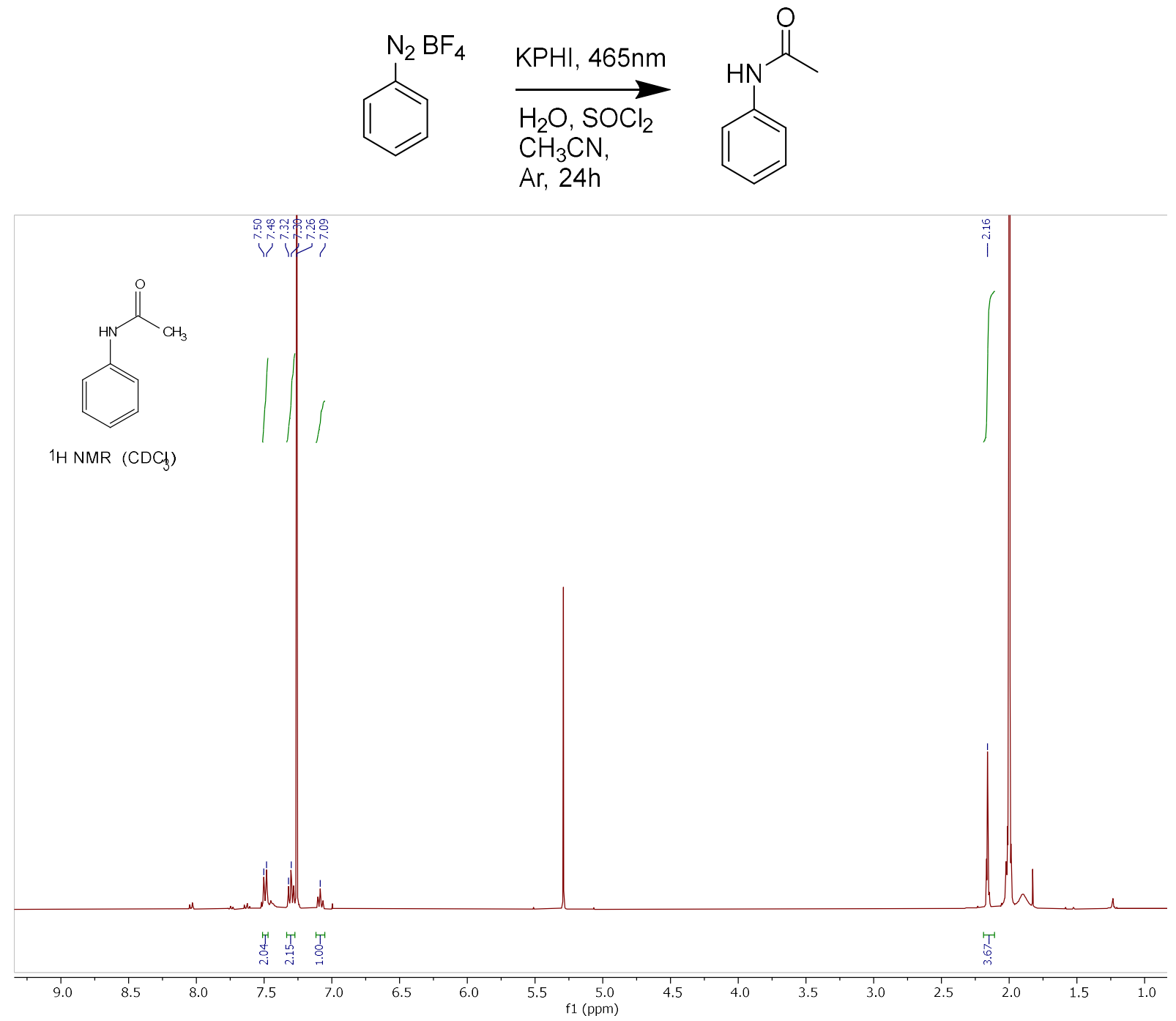

Figure S3. Scheme and ${ }^{1} \mathrm{H}$ NMR spectra of the reaction of phenyldiazonium tetrafluoroborate $1 \mathrm{e}$ with acetonitrile with formation of phenylacetamide. 


\section{DMPO-bromophenyl adduct}

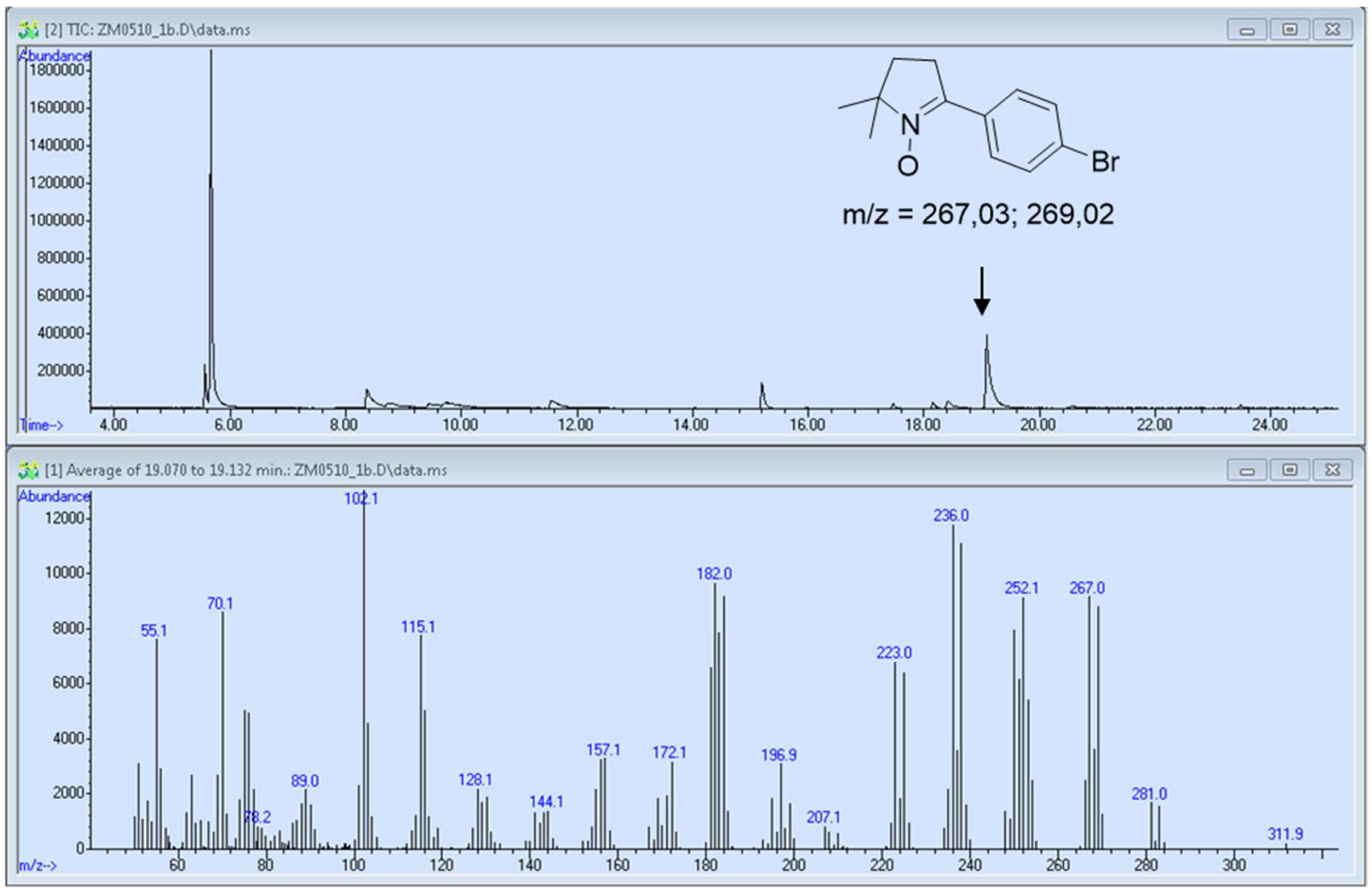

Figure S4. GC chromatogram and MS spectra of the DMPO-bromophenyl adduct. Reaction conditions: substrate $(0.025 \mathrm{mmol}) ; \mathrm{K}-\mathrm{PHI}(4 \mathrm{mg}) ; \mathrm{DMPO}(0.026 \mathrm{mmol}) ; \mathrm{Ar}$ atmosphere; irradiation with $465 \mathrm{~nm}$ LED; $18 \mathrm{~h}$. 


\section{NMR spectra}

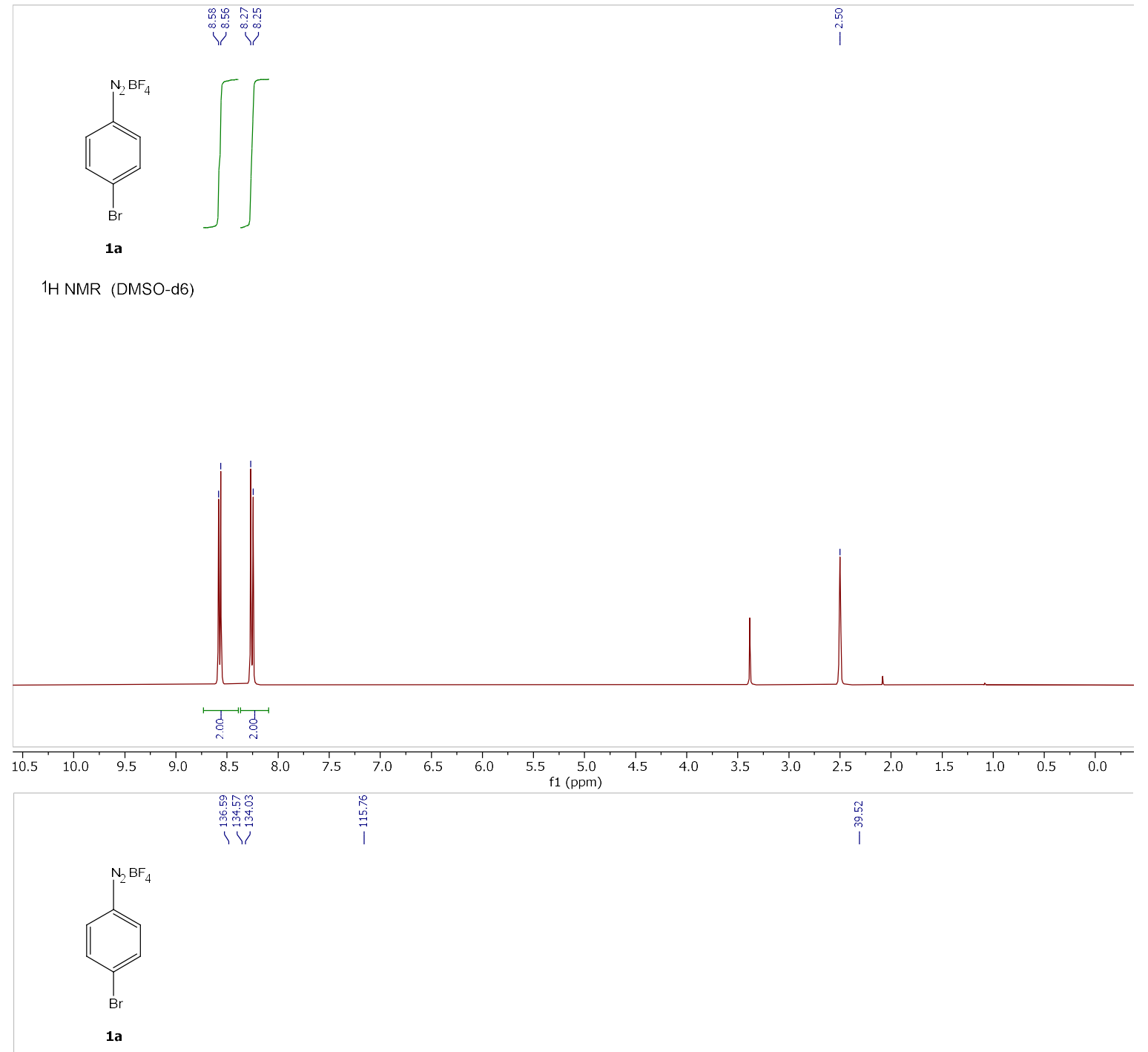

${ }^{13} \mathrm{C}$ NMR (DMSO-d6)
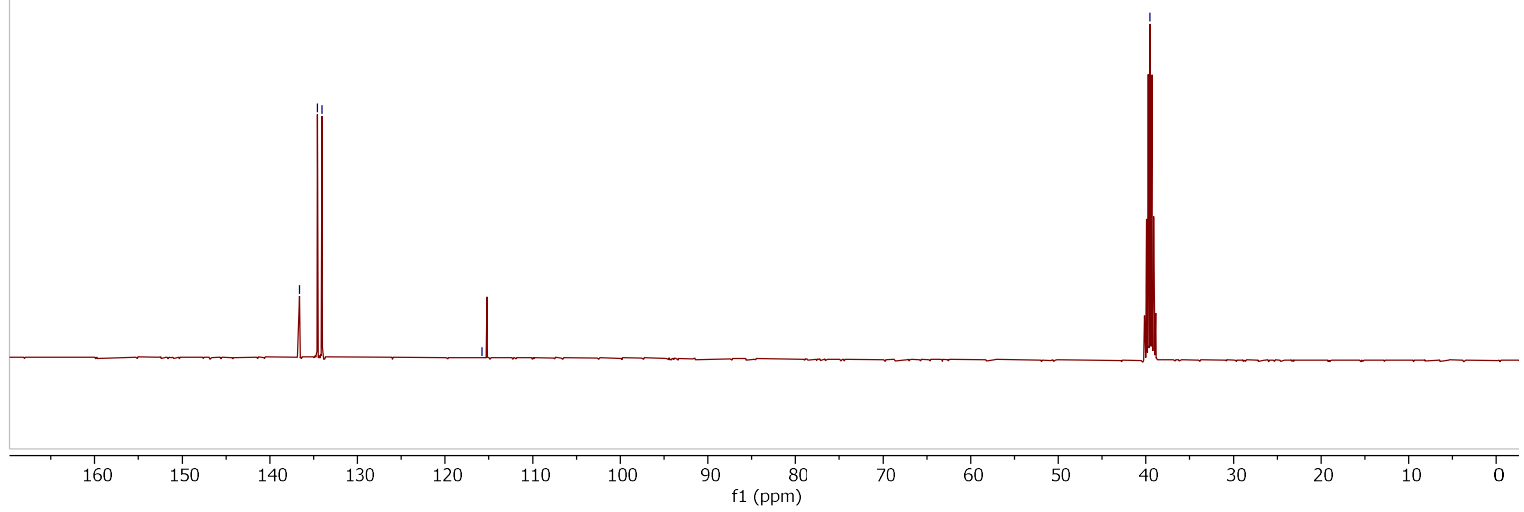

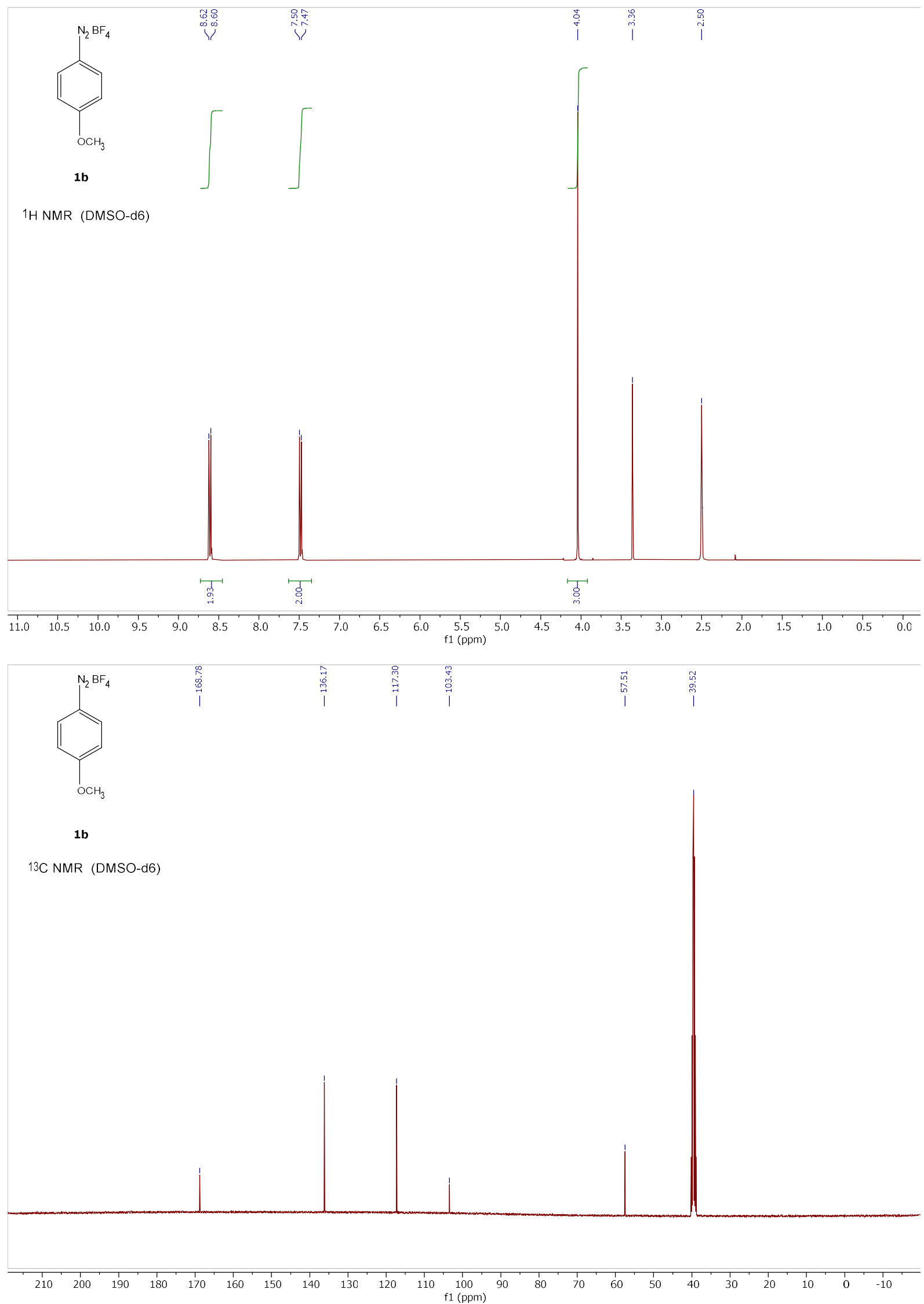


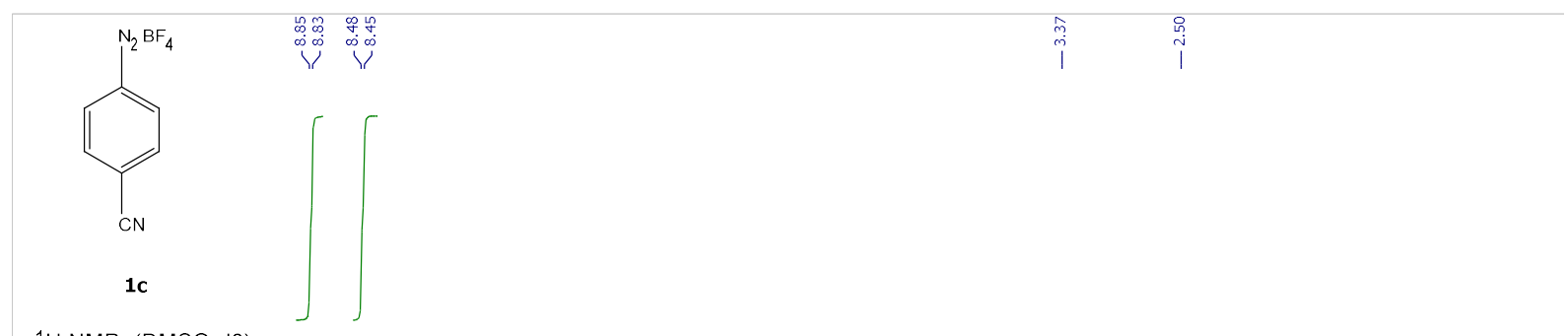

1H NMR (DMSO-d6)

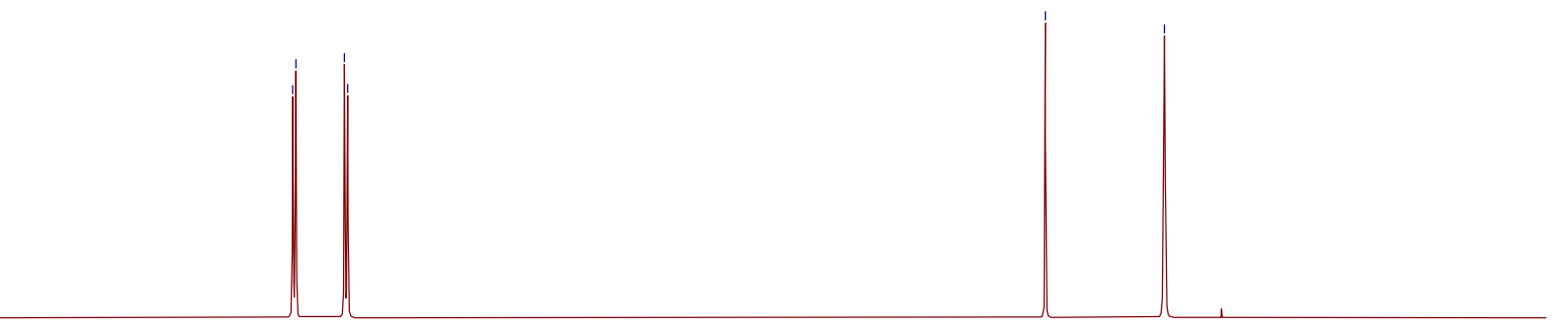

'T 'T
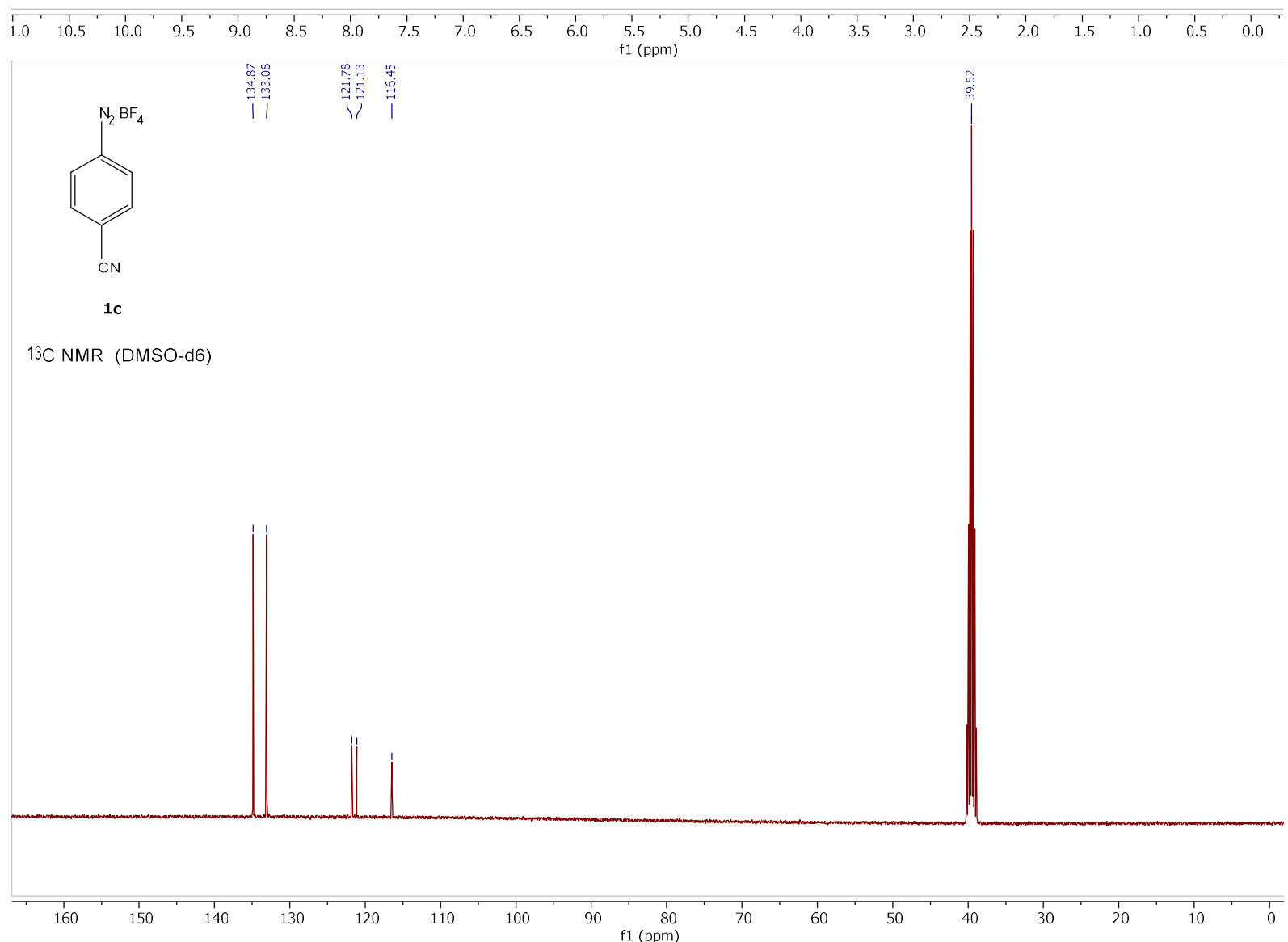

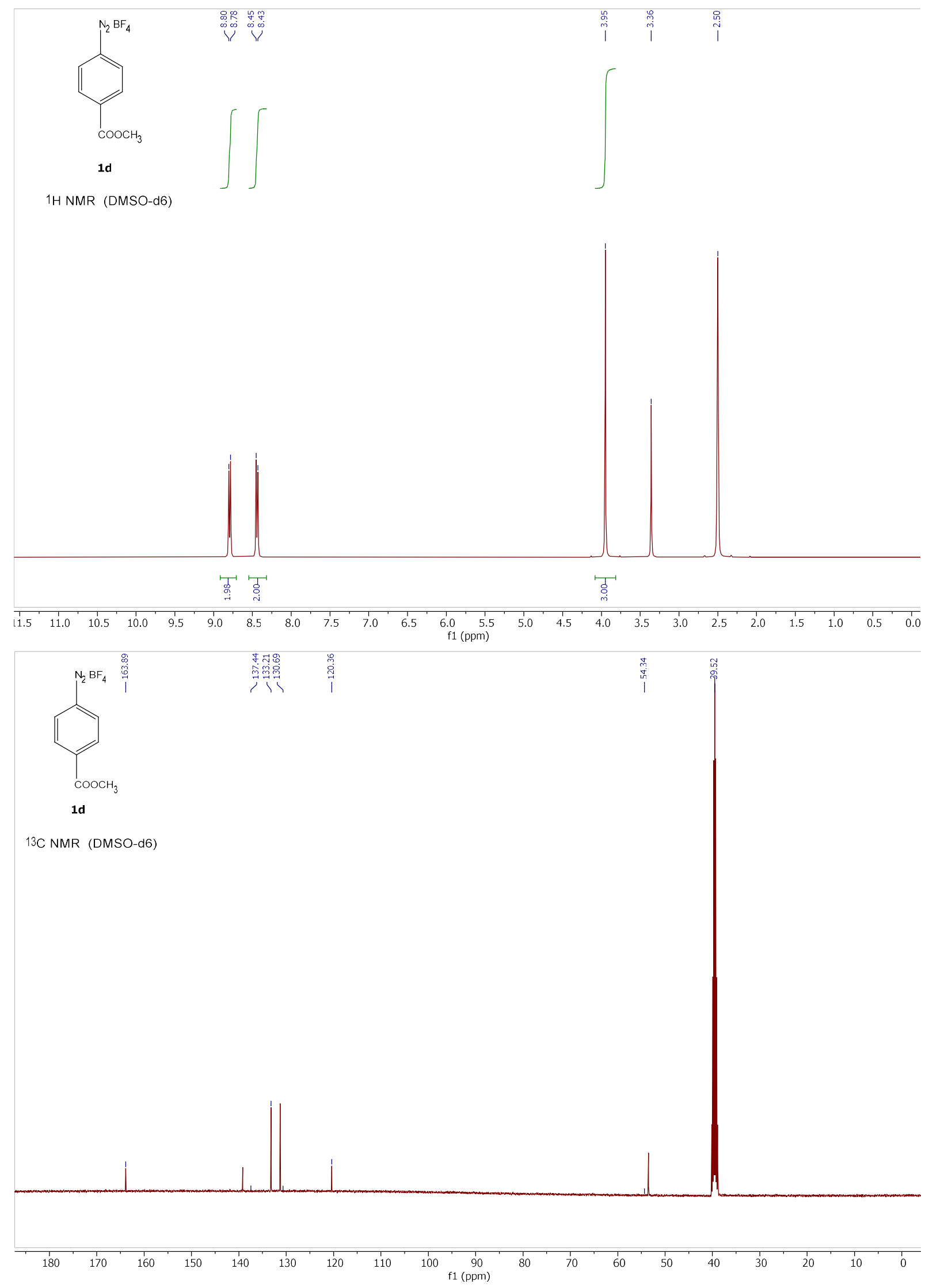


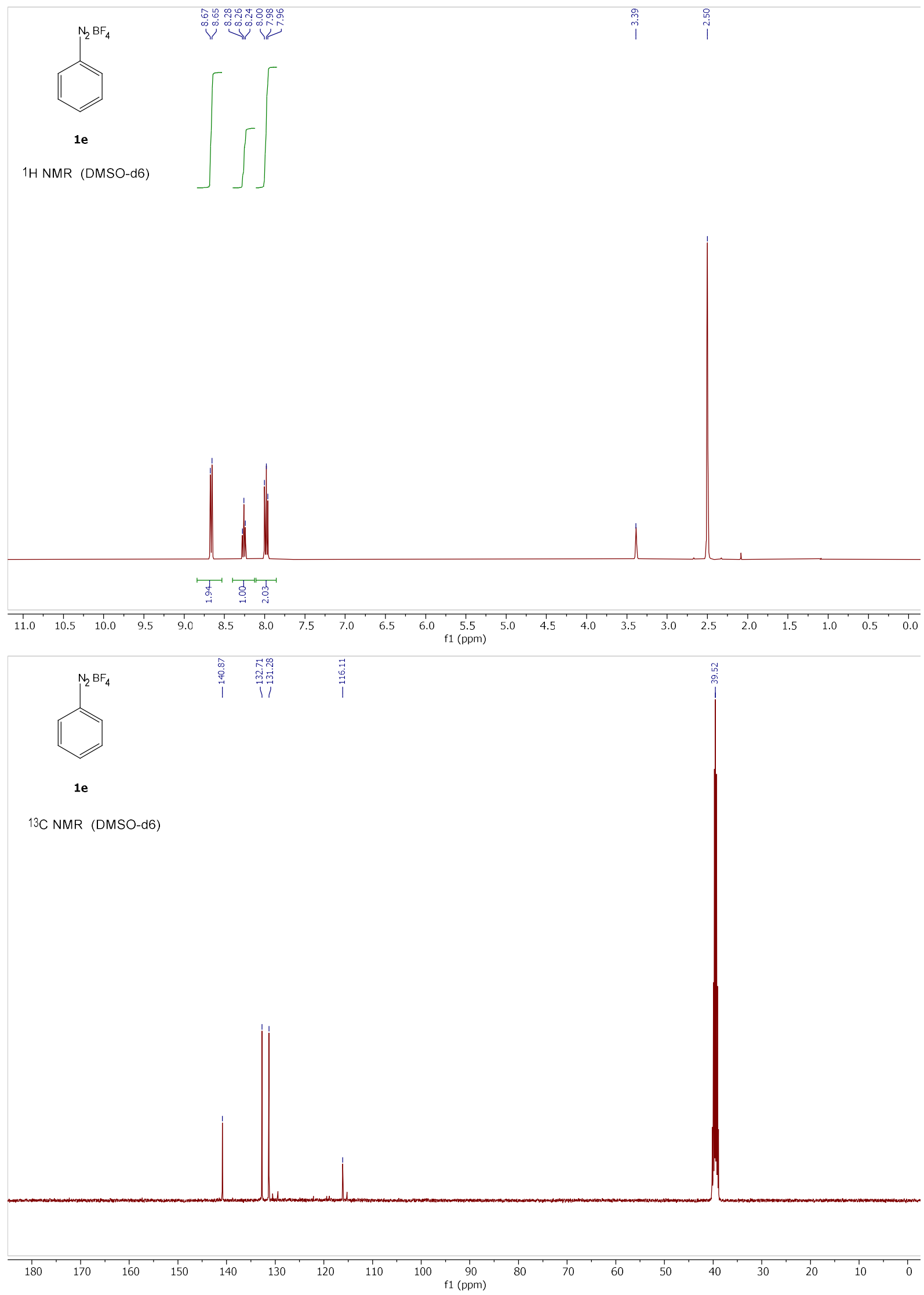



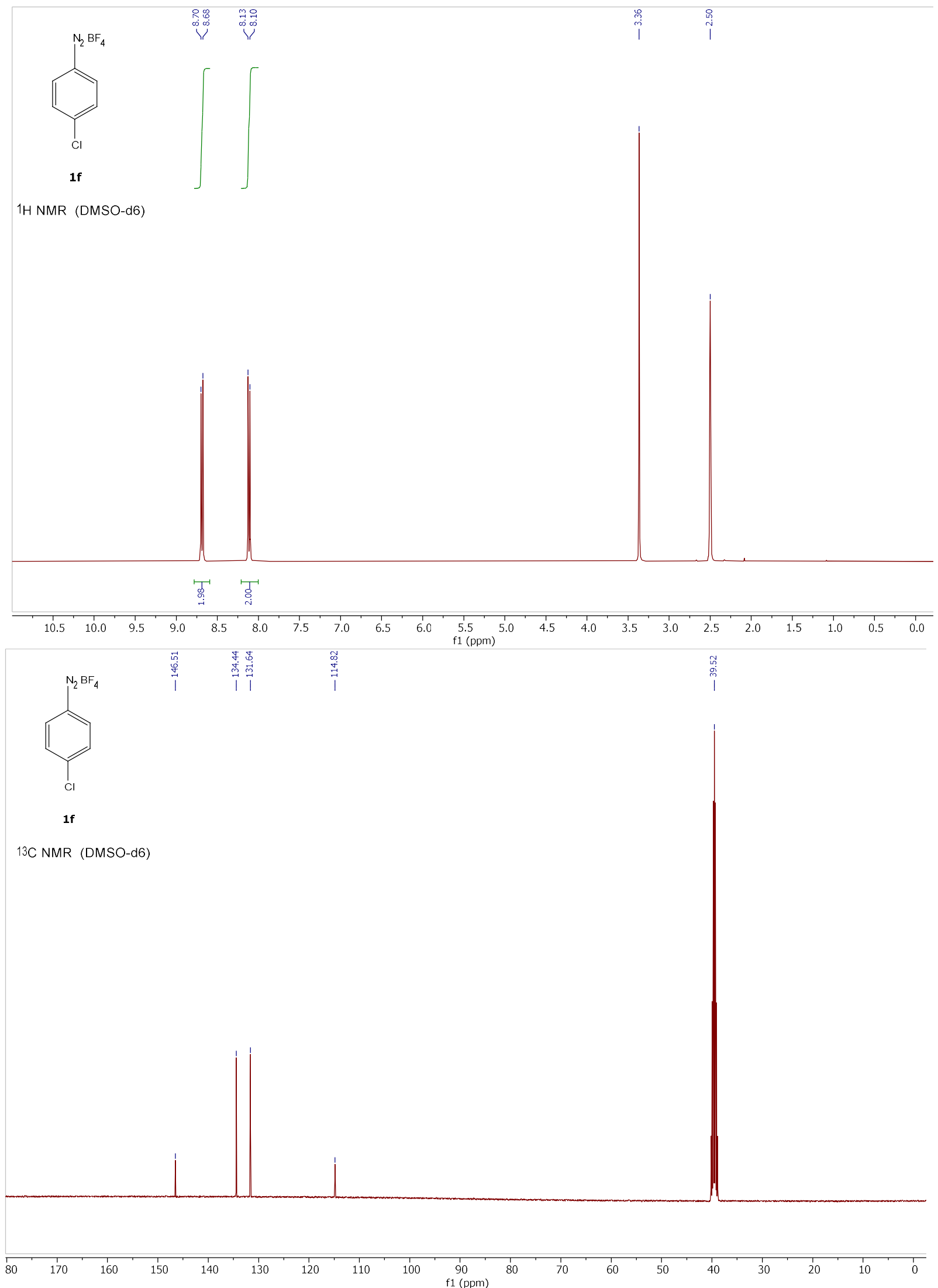

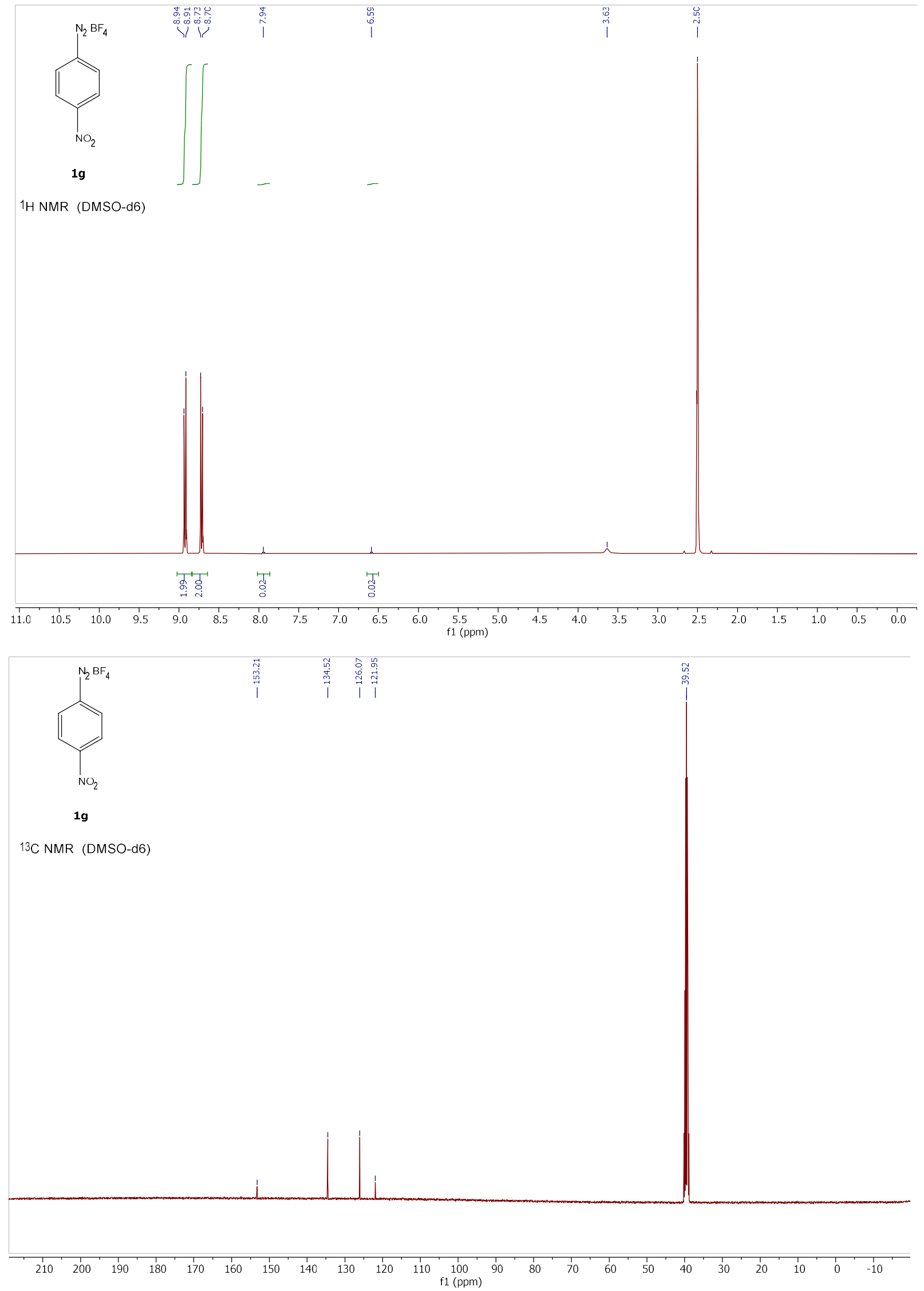

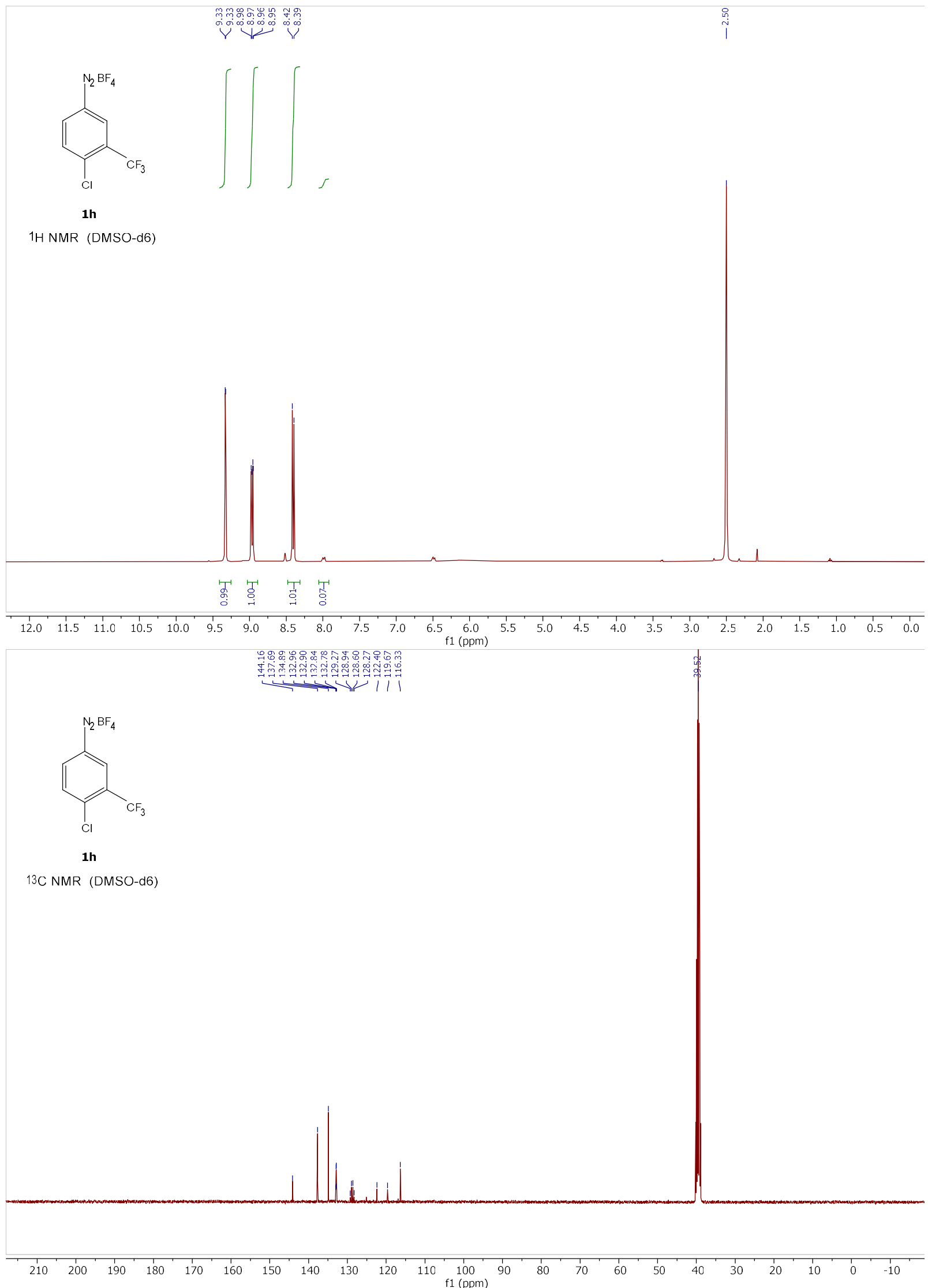


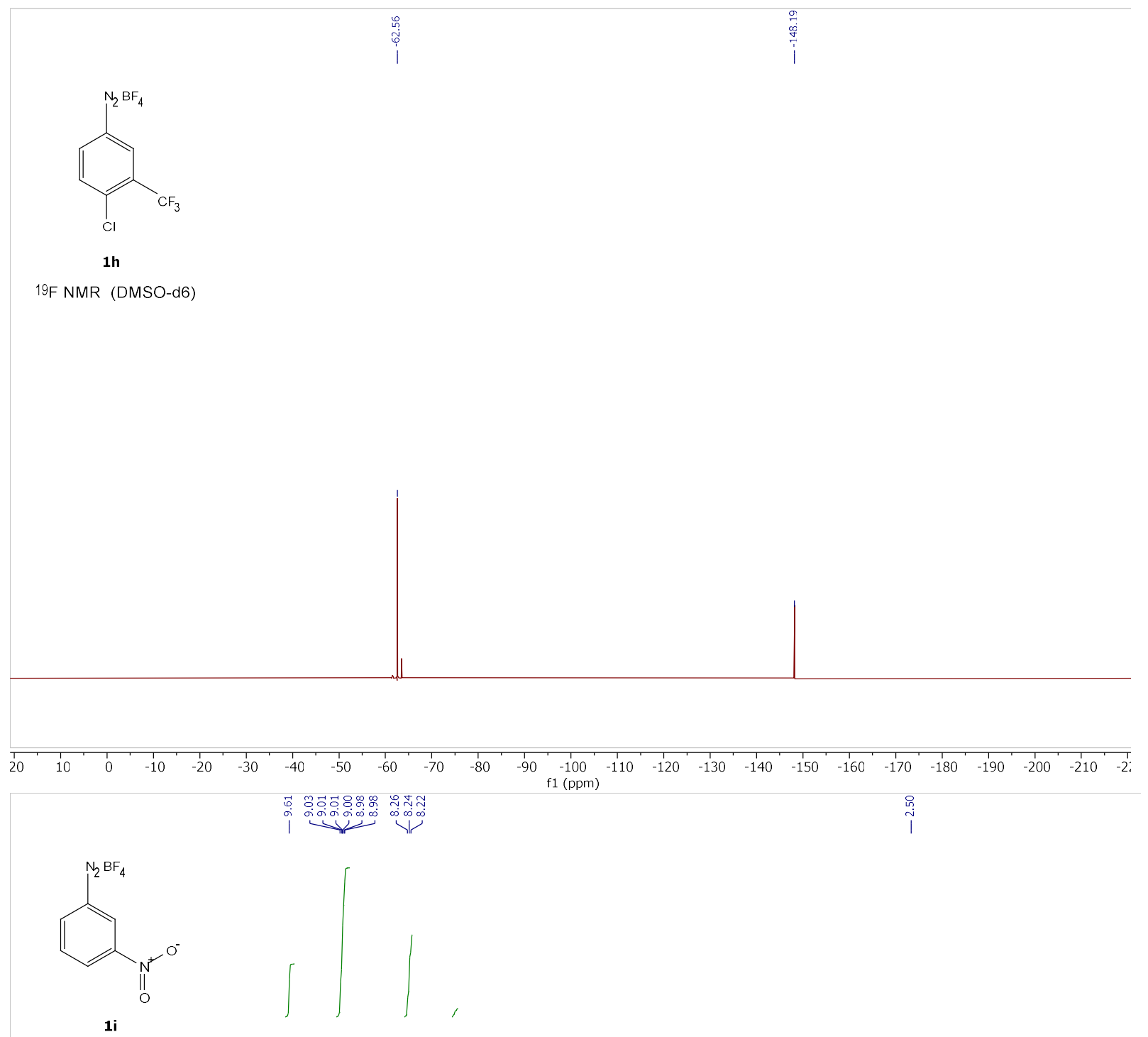

1H NMR (DMSO-d6)

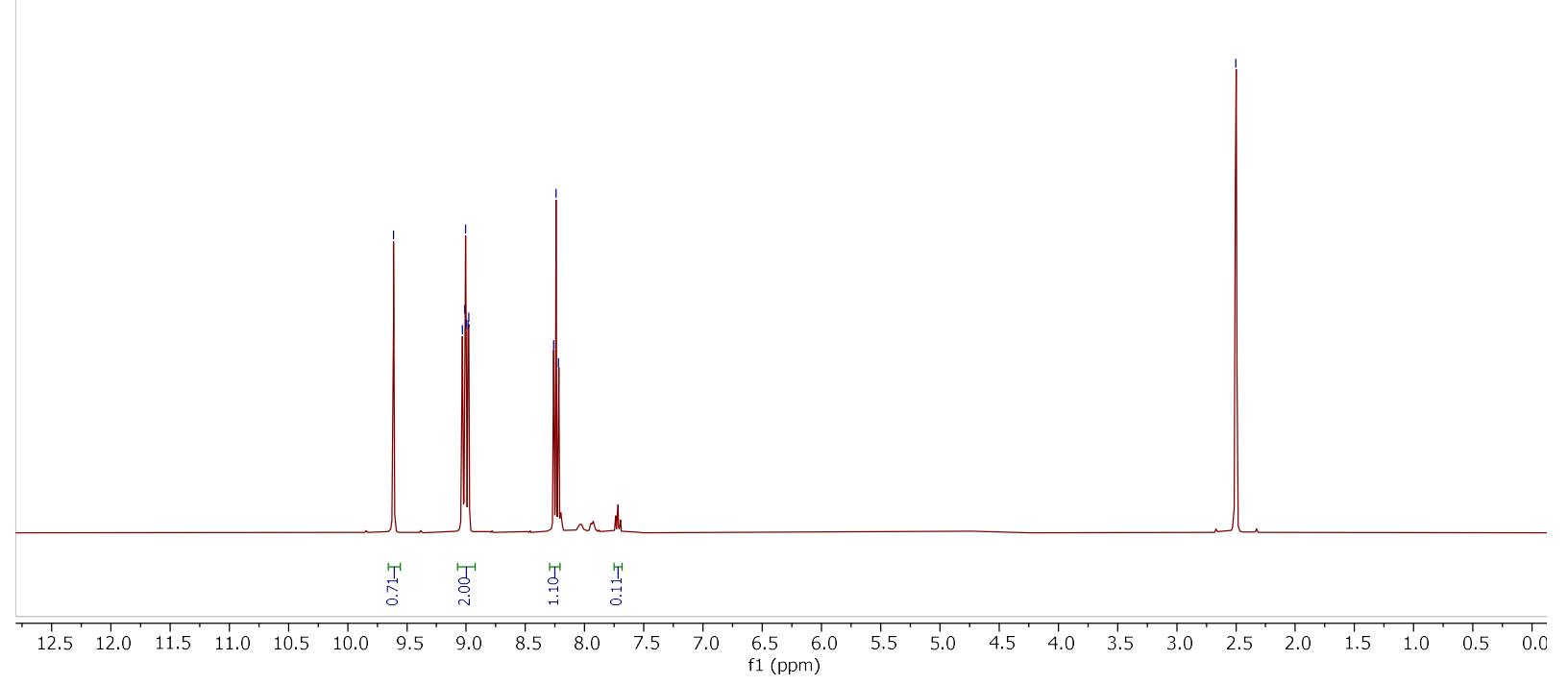



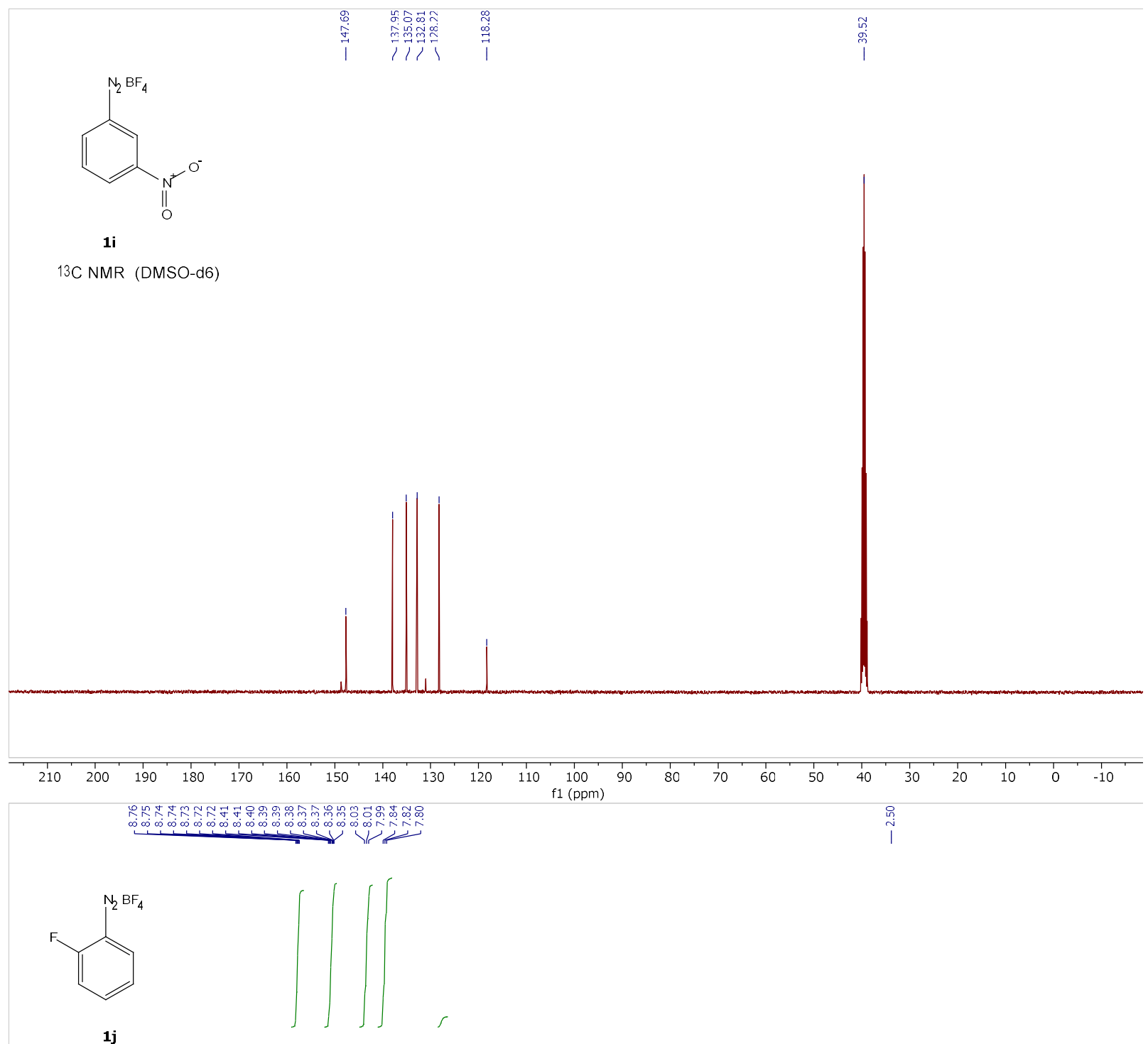

1H NMR (DMSO-d6)

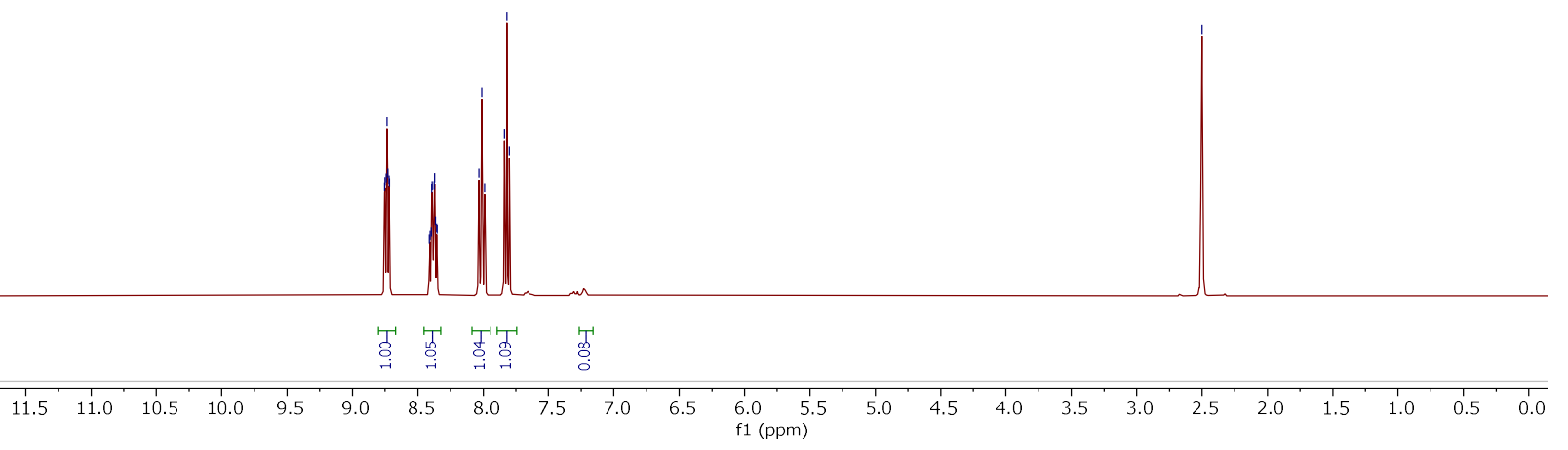



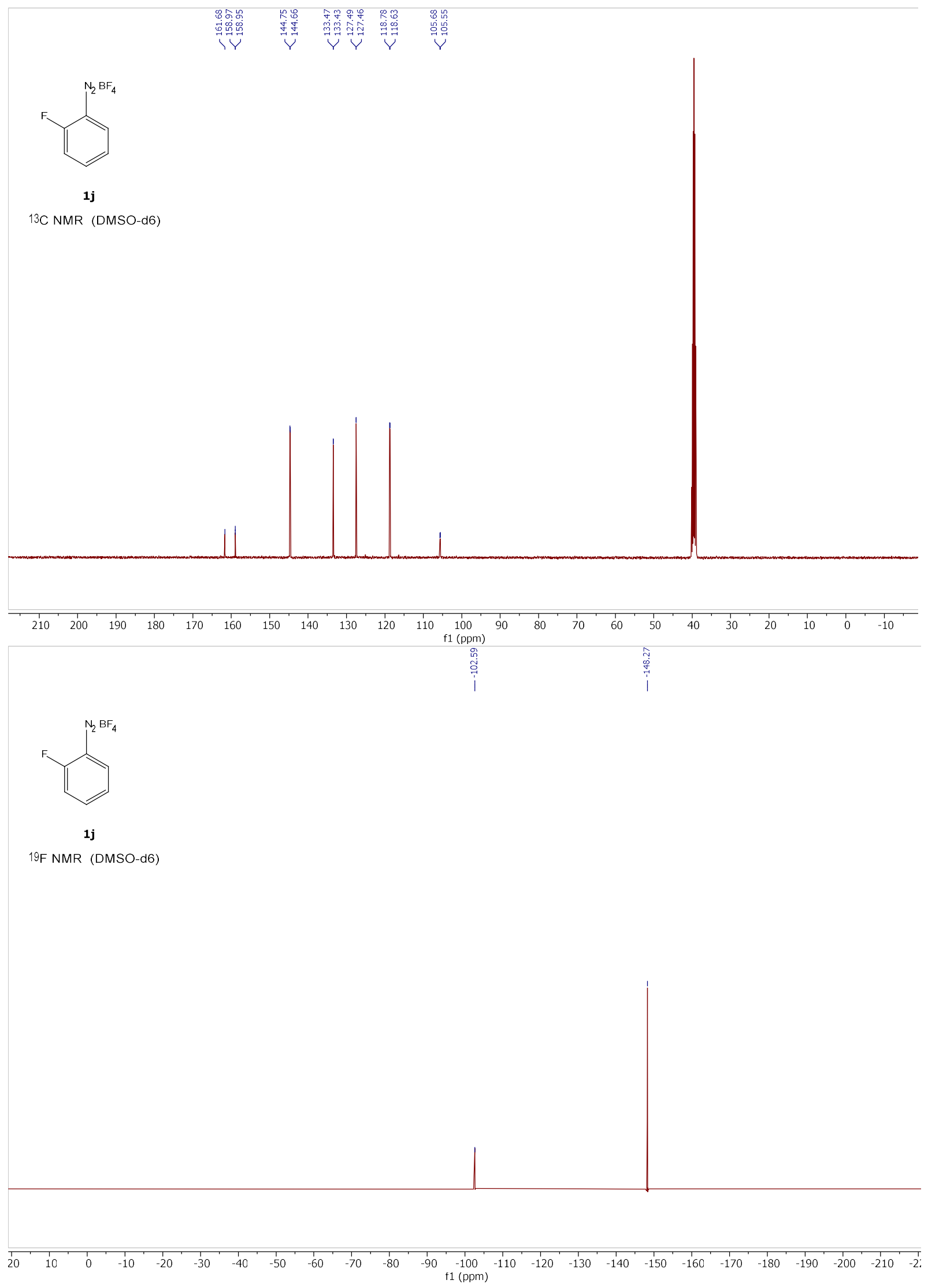


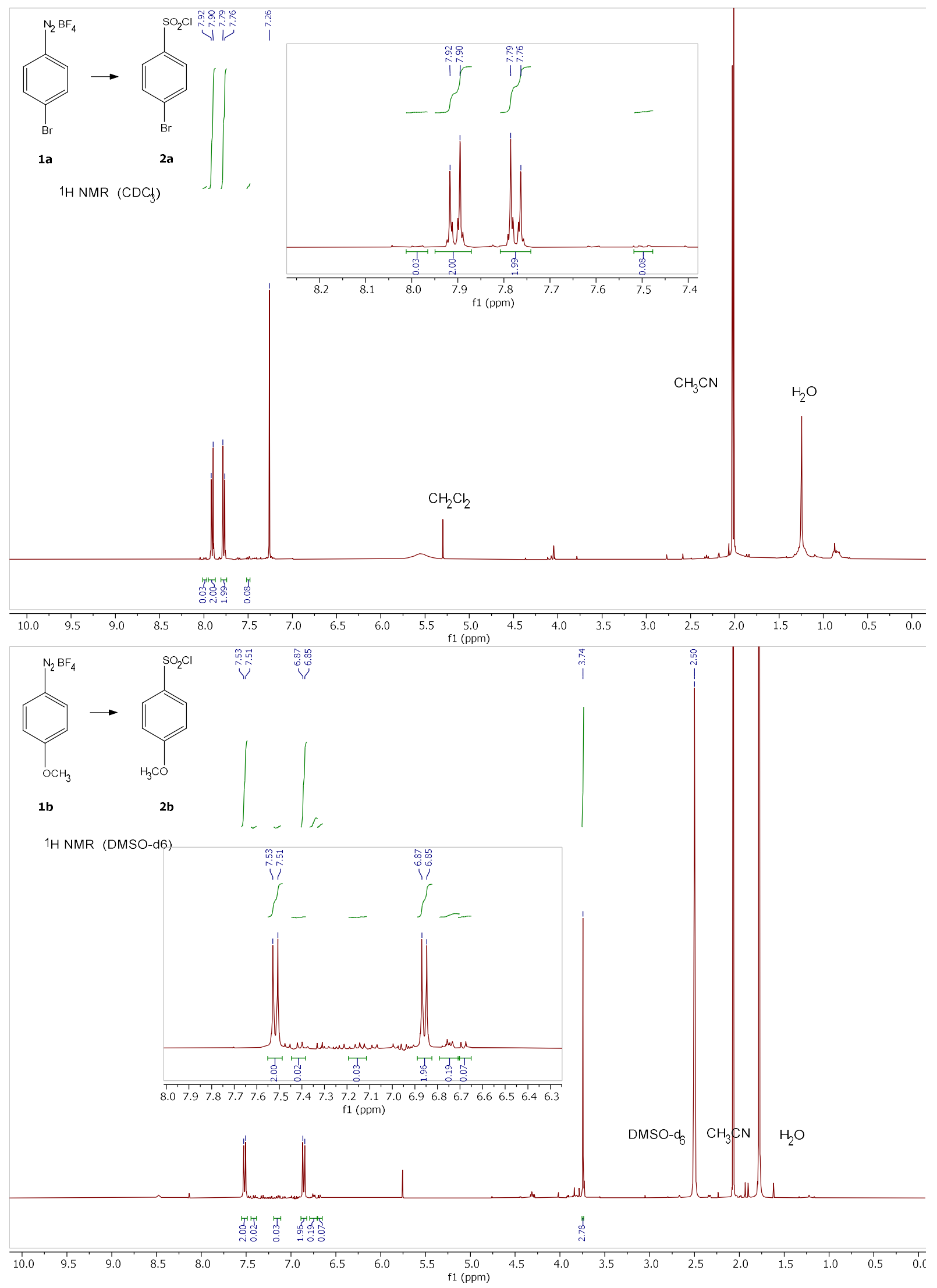




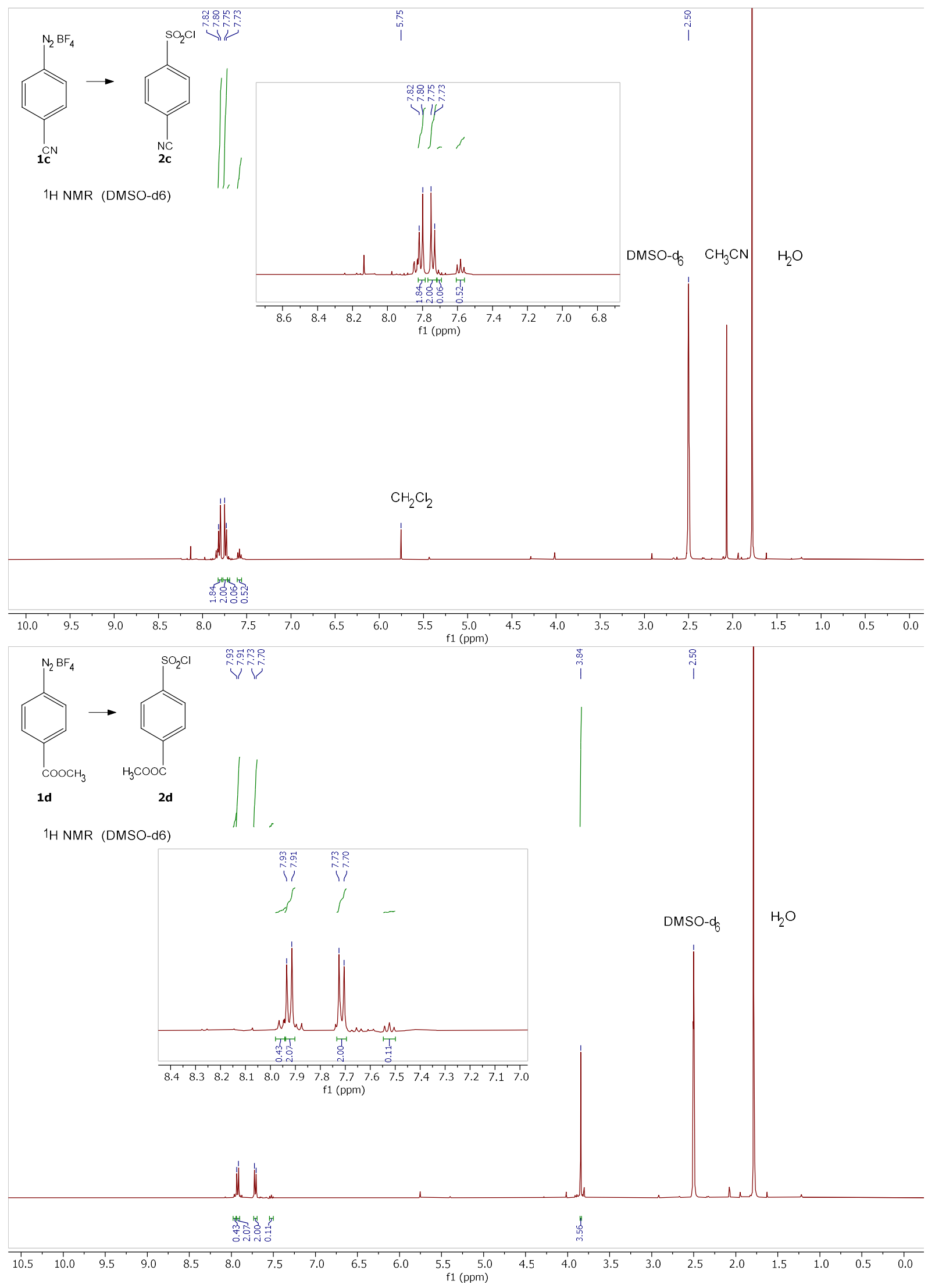




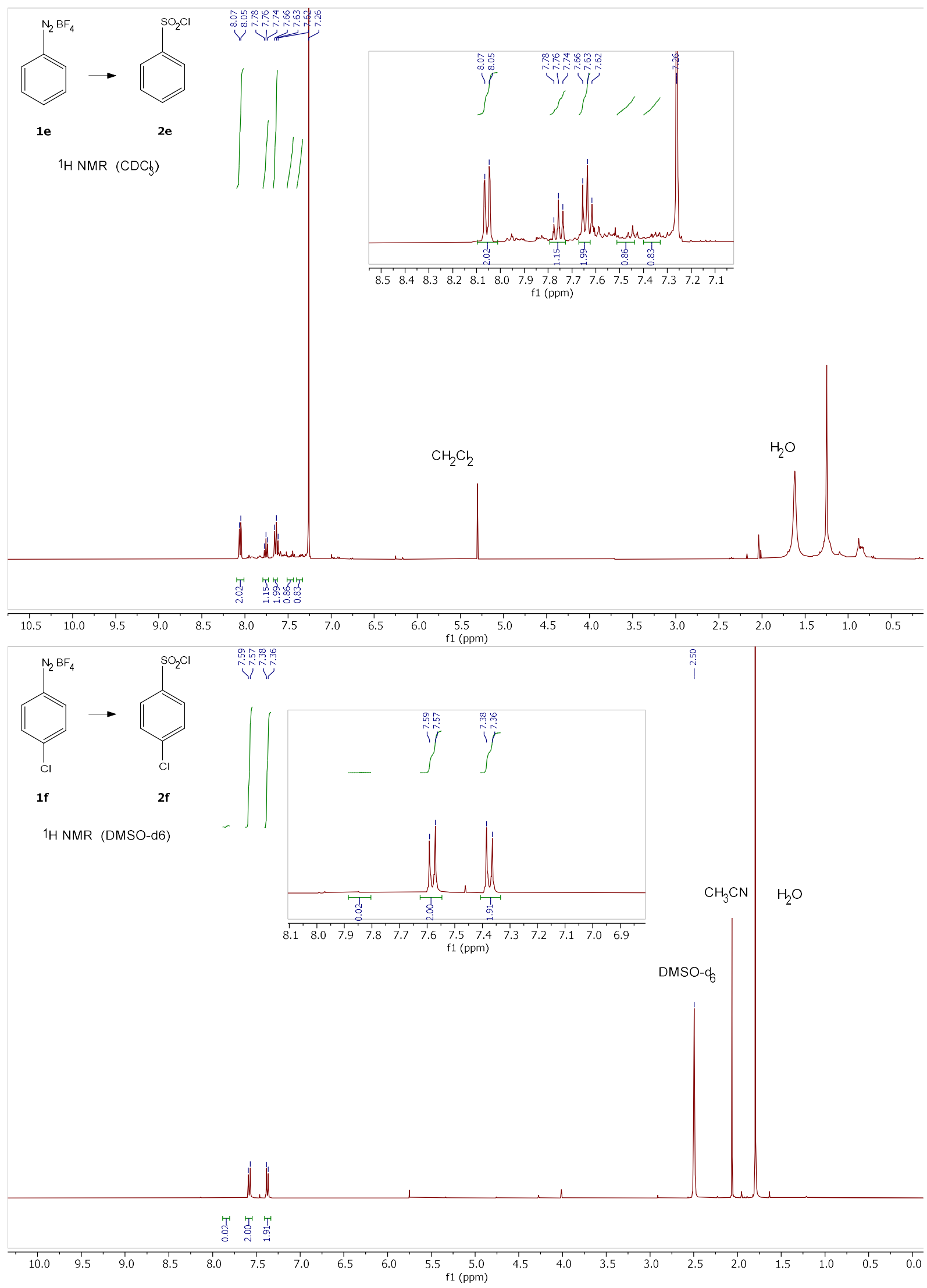



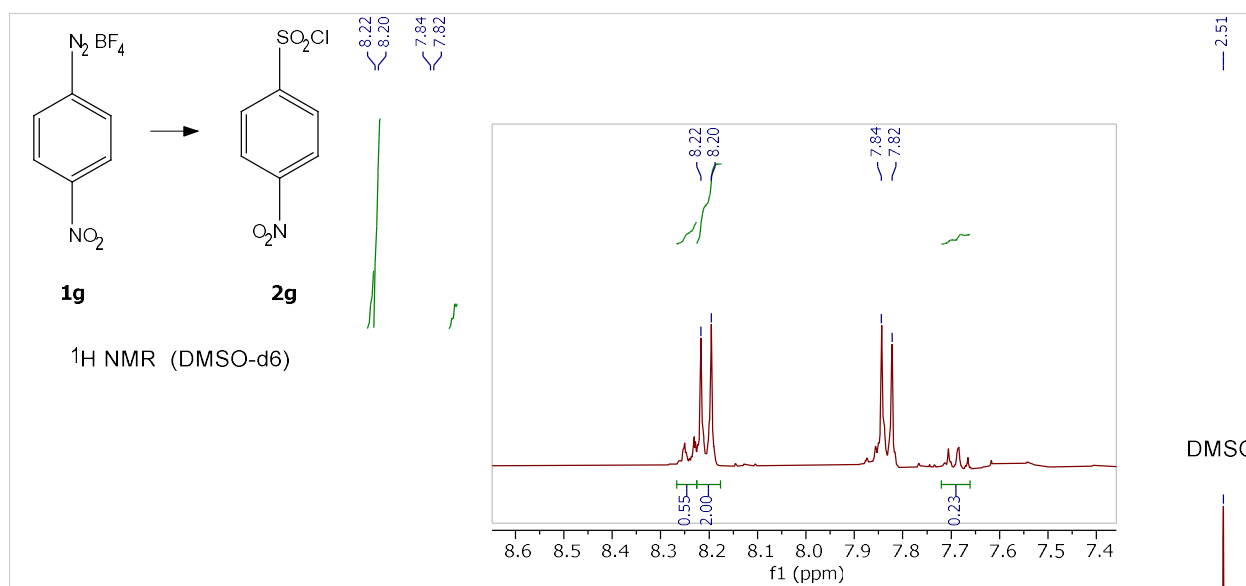

$\begin{array}{ll}\text { DMSO- }_{6} & \mathrm{H}_{2} \mathrm{O}\end{array}$
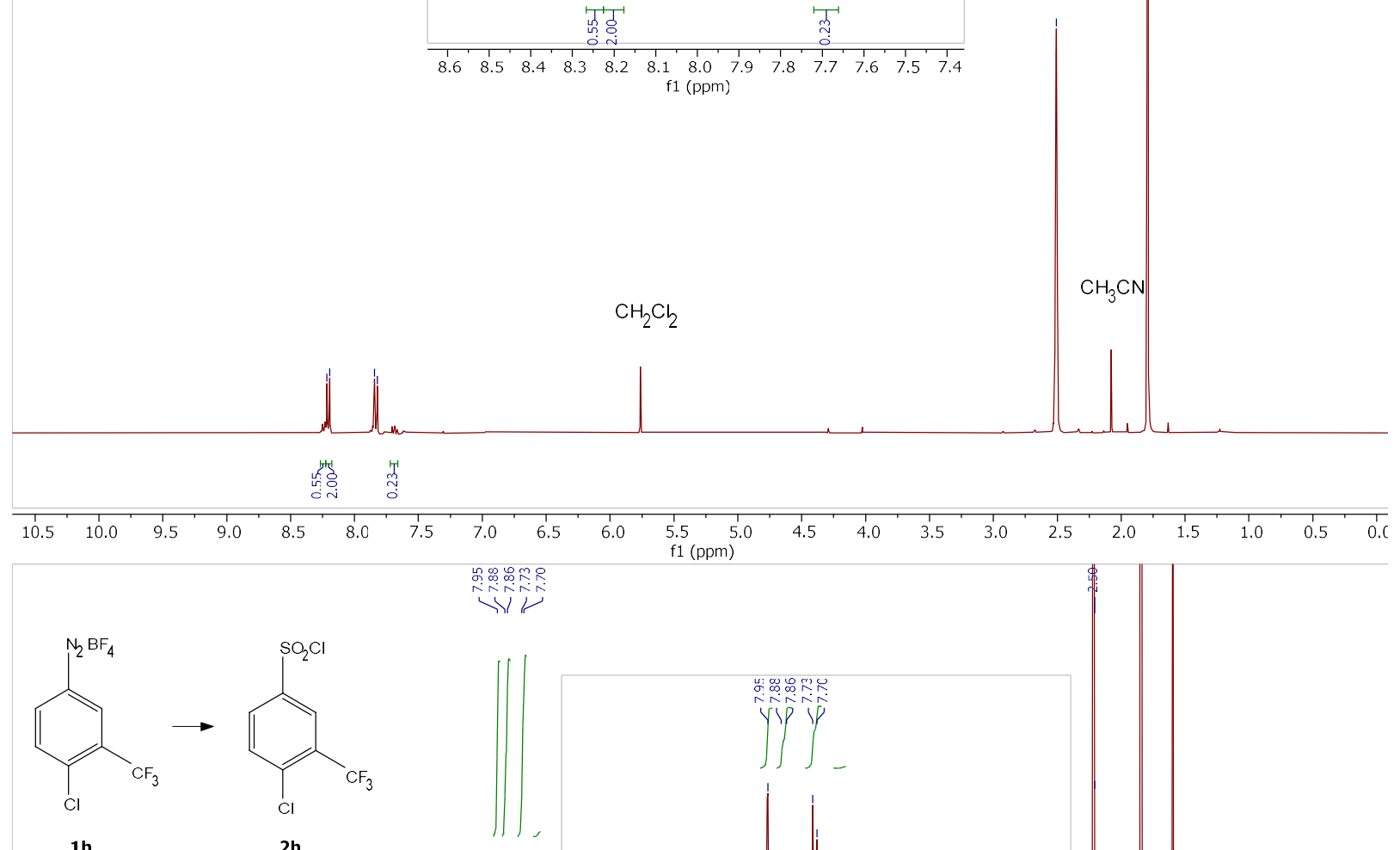

1h

2h

१H NMR (DMSO-d6)

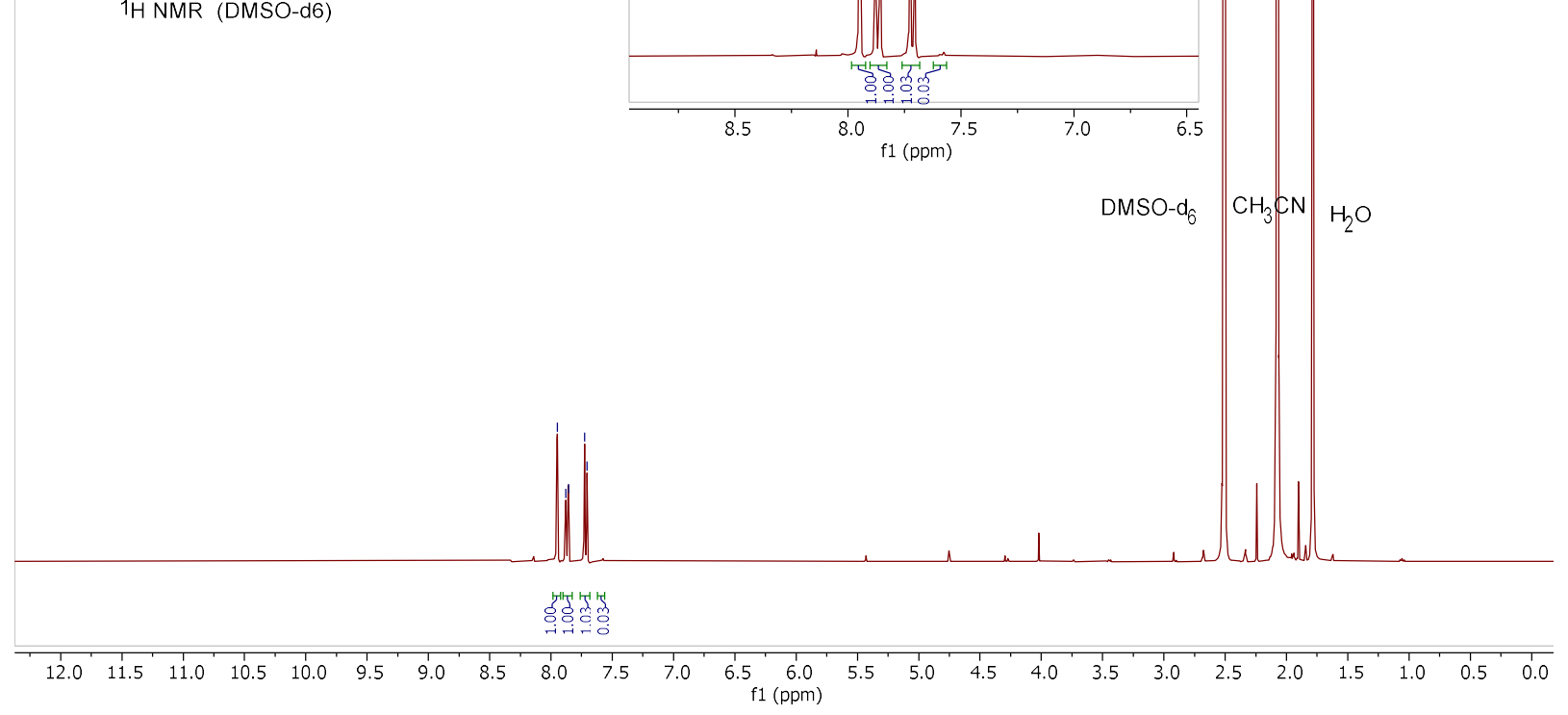




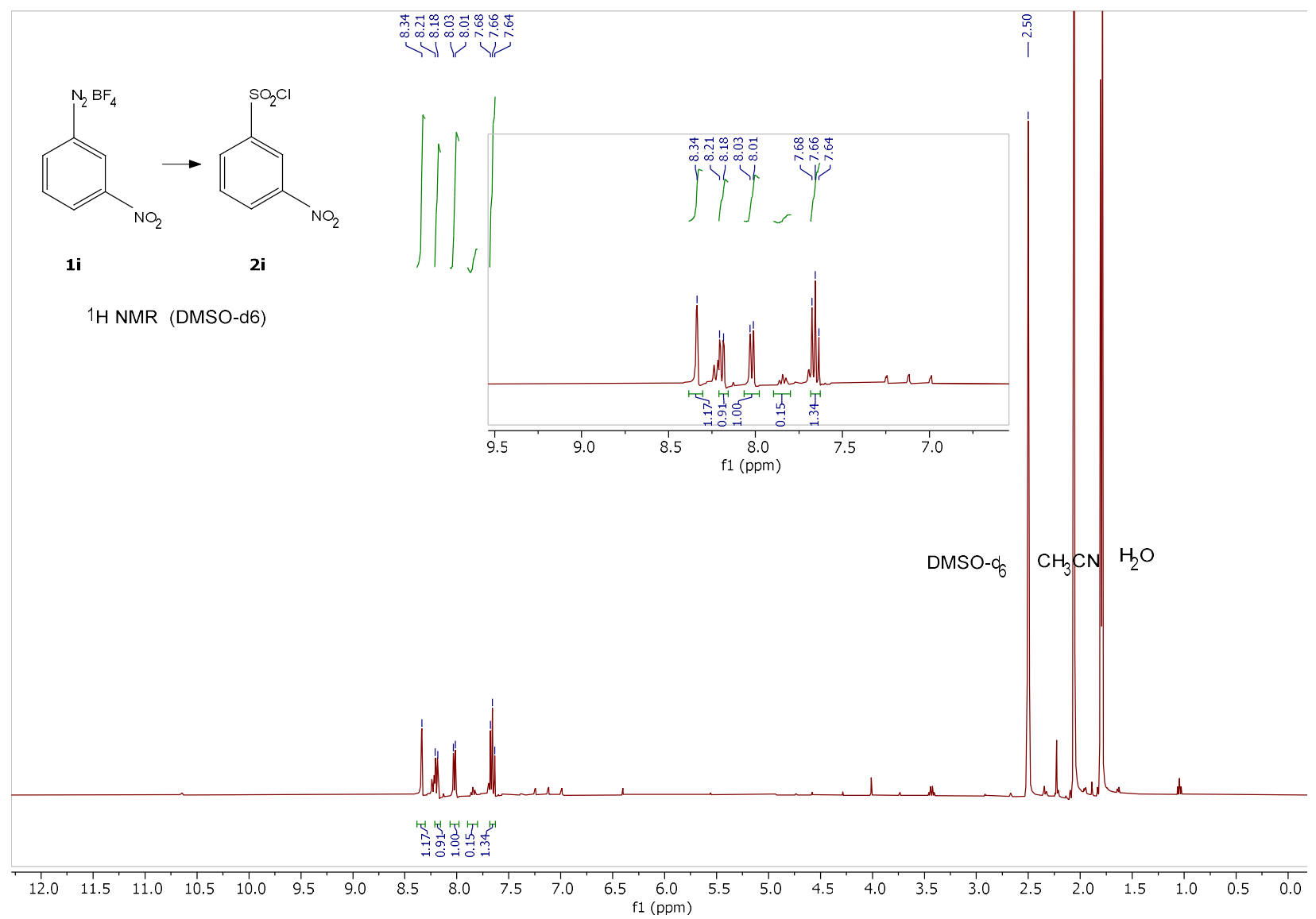




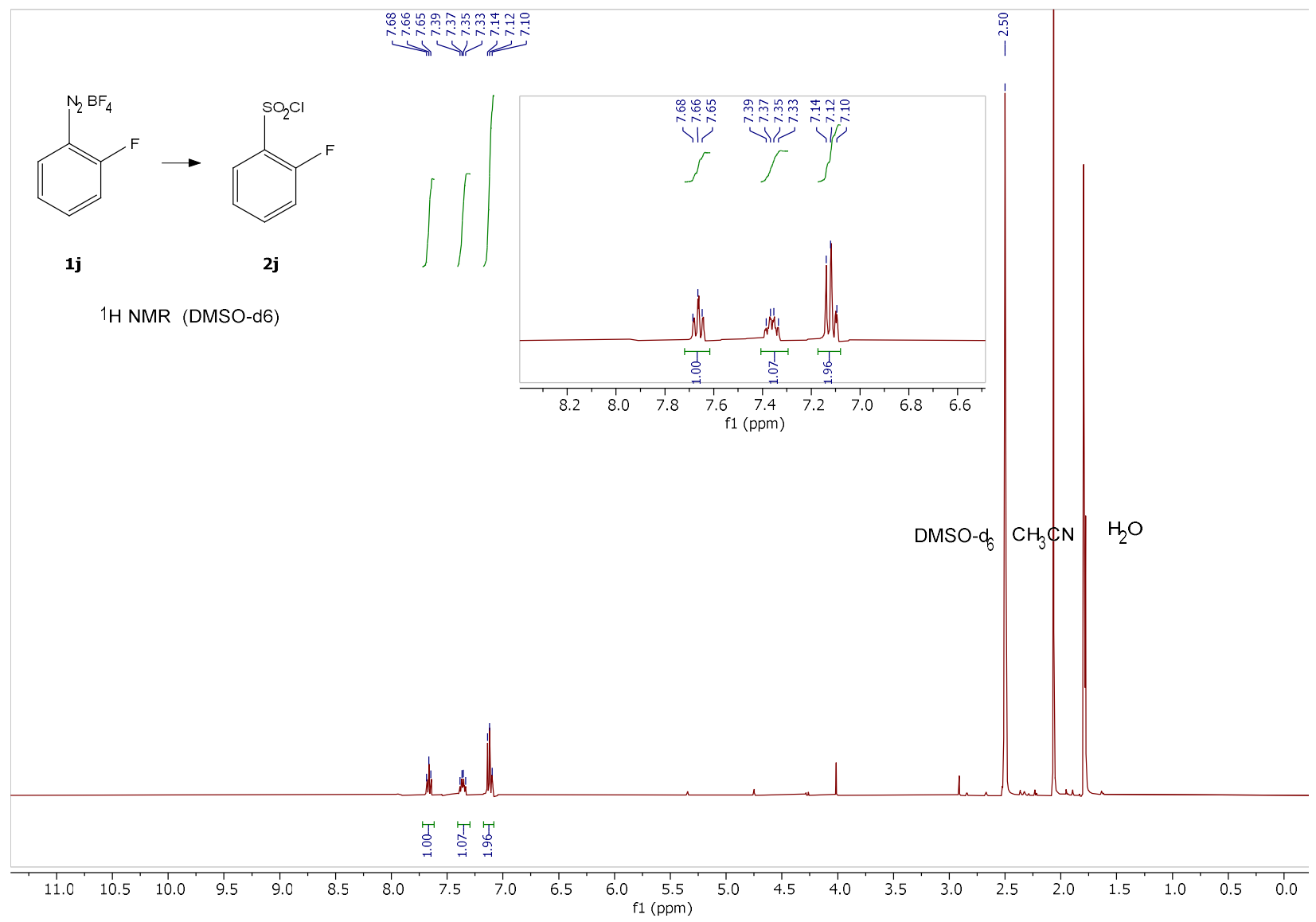

\section{References}

1. Savateev, A.; Dontsova, D.; Kurpil, B.; Antonietti, M., Highly crystalline poly(heptazine imides) by mechanochemical synthesis for photooxidation of various organic substrates using an intriguing electron acceptor - Elemental sulfur. J Catal 2017, 350, 203-211.

2. Kurpil, B.; Otte, K.; Mishchenko, A.; Lamagni, P.; Lipiński, W.; Lock, N.; Antonietti, M.; Savateev, A., Carbon nitride photocatalyzes regioselective aminium radical addition to the carbonyl bond and yields N-fused pyrroles. Nature Communications 2019, 10 (1), 945.

3. Ghosh, I.; Khamrai, J.; Savateev, A.; Shlapakov, N.; Antonietti, M.; König, B., Organic semiconductor photocatalyst can bifunctionalize arenes and heteroarenes. Science 2019, 365 (6451), 360-366.

4. Chen, Z.; Savateev, A.; Pronkin, S.; Papaefthimiou, V.; Wolff, C.; Willinger, M. G.; Willinger, E.; Neher, D.; Antonietti, M.; Dontsova, D., "The Easier the Better" Preparation of Efficient PhotocatalystsMetastable Poly(heptazine imide) Salts. Advanced Materials 2017, 29 (32).

5. Qian, L.-W.; Sun, M.; Dong, J.; Xu, Q.; Zhou, Y.; Yin, S.-F., Palladium-Catalyzed Desulfitative CrossCoupling of Arylsulfonyl Hydrazides with Terminal Alkynes: A General Approach toward Functionalized Internal Alkynes. The Journal of Organic Chemistry 2017, 82 (13), 6764-6769.

6. Hari, D. P.; Schroll, P.; Konig, B., Metal-free, visible-light-mediated direct C-H arylation of heteroarenes with aryl diazonium salts. J Am Chem Soc 2012, 134 (6), 2958-61. 
7. Hamada, T.; Yonemitsu, O., An Improved Synthesis of Arylsulfonyl Chlorides from Aryl Halides. Synthesis 1986, 1986 (10), 852-854.

8. Attia, M. I.; Timmermann, M.; Högger, P.; Herdeis, C., Design, Synthesis and Biological Activity of Azasugar-Based CD163 Ectodomain Shedding Inhibitors. Eur. J. Org. Chem. 2007, 2007 (22), 3669-3675.

9. Silva-Cuevas, C.; Perez-Arrieta, C.; Polindara-García, L. A.; Lujan-Montelongo, J. A., Sulfonyl halide synthesis by thiol oxyhalogenation using NBS/NCS - iPrOH. Tetrahedron Lett. 2017, 58 (23), 2244-2247. 